\title{
Oxidative stress signaling to chromatin in health and disease
}

Oxidative stress has a significant impact on the development and progression of common human pathologies, including cancer, diabetes, hypertension and neurodegenerative diseases. Increasing evidence suggests that oxidative stress globally influences chromatin structure, DNA methylation, enzymatic and non-enzymatic post-translational modifications of histones and DNA-binding proteins. The effects of oxidative stress on these chromatin alterations mediate a number of cellular changes, including modulation of gene expression, cell death, cell survival and mutagenesis, which are disease-driving mechanisms in human pathologies. Targeting oxidative stress-dependent pathways is thus a promising strategy for the prevention and treatment of these diseases. We summarize recent research developments connecting oxidative stress and chromatin regulation.

First draft submitted: 5 January 2016; Accepted for publication: 7 March 2016; Published online: 20 June 2016

Keywords: cancer $\bullet$ diabetes $\bullet$ DNA methylation $\bullet$ histone acetylation $\bullet$ histone methylation - oxidative stress $\bullet$ RNS $\bullet$ ROS

Oxidative stress is involved in the pathogenesis of several diseases, like Alzheimer's and Parkinson's disease [1,2], amyotrophic lateral sclerosis [3], diabetes [4,5], hypertension [6,7], autoimmune disorders [8] or cancer $[9,10]$. Many of the pathogenic effects of oxidative stress are mediated by affecting chromatin.

Chromatin is a highly regulated signal integration platform, receiving inputs from extracellular and intracellular messengers and translating these into functional outputs such as activation or repression of transcription, DNA replication, chromatin condensation or DNA repair [11]. Among others, these processes are regulated by covalent modifications of chromatin, including DNA methylation (for a review see [12]) and modifications of histones, like methylation, acetylation, phosphorylation, ubiquitination, SUMOylation or poly-ADP-ribosylation (for a review see [13]). These epigenetic marks as well as specific DNA sequences or DNA damage are recognized by effector proteins, which mediate the functional output.

Oxidative stress has been described to widely affect chromatin modifications as well as chromatin reader and repair proteins. These effects are thought to drive the physiological response to oxidative stress, but to also facilitate initiation and progression of several diseases. Here, we review how oxidative stress impacts on chromatin, how this is translated into a cellular outcome and how this is involved in common human diseases. Our analysis of the current data is focused on mechanisms directly linking oxidation or oxidative stress-mediated modification to chromatin and chromatin modifying enzymes. Effects of oxidative stress on upstream signal transduction pathways that indirectly influence chromatin have been omitted from our discussion.

\section{Oxidative stress}

In 2007, oxidative stress was redefined by Sies and Jones as 'an imbalance between oxidants
Epigenomics

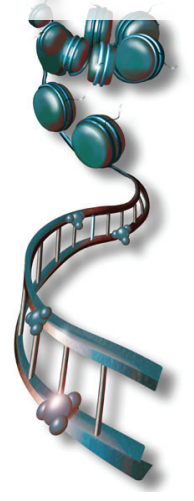

Sarah Kreuz ${ }^{1} \&$ Wolfgang Fischle ${ }^{*, 1}$

${ }^{1}$ King Abdullah University of Science \& Technology (KAUST), Environmental Epigenetics Program, Thuwal 23955-6900, Saudi Arabia

*Author for correspondence: Tel.: +966128082498

wolfgang.fischle@kaust.edu.sa
Future
Medicine $\mathrm{fs}$ par of 


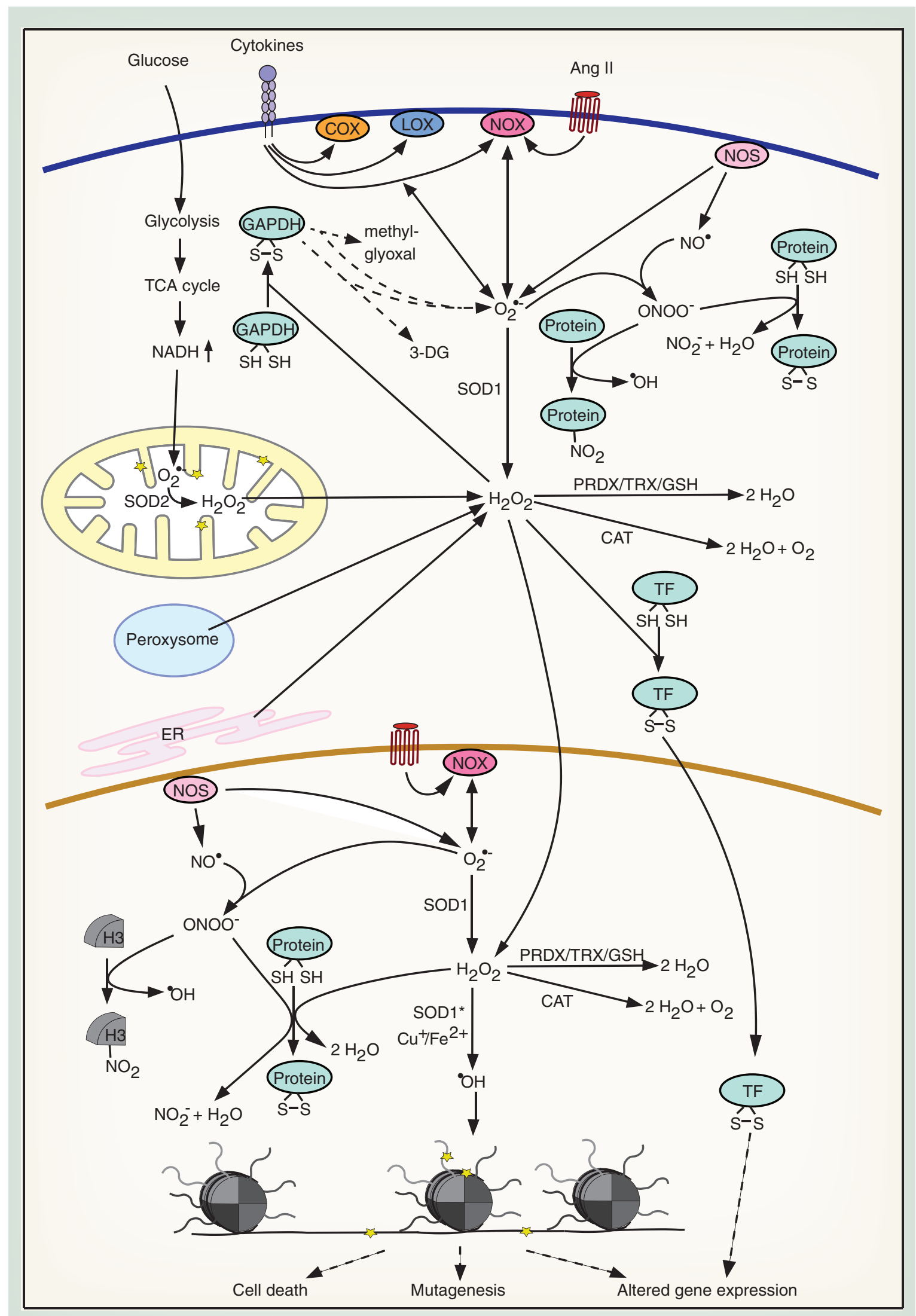


Figure 1. Causes and consequences of elevated nuclear and cytoplasmic reactive oxygen species (see facing page). Many pathogenic factors and pathophysiological processes lead to an increase in cytoplasmic and nuclear ROS. ROS can be detoxified, function as second messengers or damaging agents, altering gene expression, inducing mutagenesis or cell death. Stars indicate macromolecular damage.

3-DG: 3-deoxyglucosone; Ang II: Angiotensin II; CAT: Catalase; COX: Cyclooxygenase; ER: Endoplasmic reticulum; GAPDH: Glyceraldehyde-3-phosphate dehydrogenase; GSH: Glutathione; LOX: Lipoxygenase; NO: Nitric oxide; NOS: Nitric oxide synthase; NOX: NADPH oxidase; PRDX: Peroxiredoxin; ROS: Reactive oxygen species; SOD: Superoxide dismutase; SOD*: Mutated SOD; TF: Transcription factor; TRX: Thioredoxin.

and antioxidants in favor of the oxidants, leading to a disruption of redox signaling and control and/or molecular damage' [14]. Physiologically, most cellular compartments are reducing environments $[15,16]$, which are rich in antioxidants, like glutathione (GSH), ascorbic acid (vitamin C) or $\alpha$-tocopherol (vitamin E) and antioxidant enzymes like peroxiredoxins, thioredoxins, superoxide dismutases (SODs) and catalase $[17,18]$. Consequently, most cysteines in intracellular proteins are in the reduced state under normal conditions to facilitate proper protein function $[16,19]$. Further, oxidative damage to DNA, RNA and lipids is prevented in such an environment because the antioxidant systems normally scavenge oxidants, like reactive oxygen or nitrogen species (ROS, RNS). ROS are produced when single electrons are transferred to oxygen, leading to the generation of the relatively inert superoxide radical $\left(\mathrm{O}_{2}^{--}\right)$[20-23], the more reactive hydrogen peroxide $\left(\mathrm{H}_{2} \mathrm{O}_{2}\right)$ and the highly reactive and damaging hydroxyl radical $\left({ }^{\circ} \mathrm{OH}\right)$ [24]. Damaging RNS result from the reaction of nitric oxide $\left(\mathrm{NO}^{*}\right)$ with $\mathrm{O}_{2}{ }^{-}$, generating the highly reactive peroxynitrite (ONOO-) [25].

\section{ROS \& RNS as second messengers}

Due to their intermediate reactivity, $\mathrm{H}_{2} \mathrm{O}_{2}$ and $\mathrm{NO}^{\circ}$ are important physiological second messengers. Several signal transduction pathways activate NADPH oxidases (NOX) in the cytosol and the nucleus and their sole function is to produce $\mathrm{O}_{2}^{--}$, which is then dismutated to $\mathrm{H}_{2} \mathrm{O}_{2}$ (Figure 1) $[24,26,27] . \mathrm{H}_{2} \mathrm{O}_{2}$ has limited toxicity because it selectively oxidizes cysteine residues in specialized protein environments, whose $\mathrm{pK}_{\mathrm{a}}$ is particularly low, so that they exist as thiolate anions $\left(S^{\mathrm{a}}\right)$ at physiological $\mathrm{pH}[28,29]$. Oxidized cysteines often form disulfide bonds, altering protein folding and function and thus serving as ROS sensors (Figure 1) [29]. This mechanism of redox regulation has been shown for a number of transcription factors, kinases, protein phosphatases and matrix metalloproteinases [30-33] (see [34,35] for reviews).

$\mathrm{NO}^{*}$ is generated in the cytosol and the nucleus through the action of nitric oxide synthases (NOS) (Figure 1) [36,37]. NOS are dependent on $\mathrm{Ca}^{2+} / \mathrm{calmod}-$ ulin and the cofactor tetrahydrobiopterin $\left(\mathrm{BH}_{4}\right)$. They catalyze the production of $\mathrm{NO}^{\bullet}$ from $\mathrm{O}_{2}$, arginine and NADPH [38]. Similar to $\mathrm{H}_{2} \mathrm{O}_{2}$, NO' is not highly reactive toward macromolecules and is mainly implicated in physiological cellular signaling [39].

\section{Pathways leading to increased ROS/RNS production}

Although some ROS/RNS are important signaling molecules, overproduction of these molecules or pathological depletion of antioxidants can lead to oxidative stress. In eukaryotes, unintended ROS production is mainly a consequence of the oxidative metabolism. While oxygen itself has a very low reactivity [40], many cellular enzymes are capable of inadvertently transferring a single electron to $\mathrm{O}_{2}$, leading to generation of $\mathrm{O}_{2}{ }^{--}$[20-23], which can damage biomolecules by either oxidizing or reducing them [24]. Physiologically, $\mathrm{O}_{2}^{--}$is rapidly detoxified by $\mathrm{SOD}$ in the mitochondria, the cytosol and the nucleus to yield $\mathrm{H}_{2} \mathrm{O}_{2}[20,41] . \mathrm{H}_{2} \mathrm{O}_{2}$ is also produced by a number of metabolic enzymes, like the peroxisomal Acyl-CoA oxidase, or through protein oxidation in the ER (Figure 1) [42-44]. In contrast to $\mathrm{O}_{2}{ }^{-}$, $\mathrm{H}_{2} \mathrm{O}_{2}$ can diffuse through aquaporins to cross organelle membranes and enter the cytosol and the nucleus [45]. $\mathrm{H}_{2} \mathrm{O}_{2}$ is disproportionated by catalase or removed through the peroxiredoxin/thioredoxin and GSH systems (Figure 1) [46,47]. If $\mathrm{H}_{2} \mathrm{O}_{2}$ is not detoxified, it can be converted into ${ }^{\circ} \mathrm{OH}$ via the $\mathrm{Cu}^{+}$- or $\mathrm{Fe}^{2+}$-catalyzed Fenton reaction. ${ }^{\circ} \mathrm{OH}$ is highly toxic and rapidly oxidizes and damages DNA, lipids or proteins (Figure 1) [29]. Similarly, $\mathrm{ONOO}^{-}$damages proteins through tyrosine nitration and disruption of iron-sulfur clusters. Also, its potential to oxidize perceptible cytosines is much higher than that of $\mathrm{H}_{2} \mathrm{O}_{2}$ (Figure 1) [25].

One of the main causes of oxidative stress is mitochondrial dysfunction, resulting from damaged mitochondria $[1,2,6,10]$ or from hyperglycemia-induced alterations in the cellular metabolism in diabetes (Figure 1) [4,5]. Other major contributors to oxidative stress are cytosolic and nuclear enzymes. Enhanced production of ROS by hyperactivated NOX, 'uncoupled' NOS or other enzymes, like lipoxygenase (LOX), cyclooxygenase (COX) or xanthine oxidase, can be the cause of oxidative stress [6,7,9]. Among others, the activation of NOX, COX and LOX can be driven by acute or chronic inflammation through the exposure of cells to cytokines [48,49] or by hormones like angiotensin II in hypertension (Figure 1) [50]. NOS can be uncoupled and release $\mathrm{O}_{2}{ }^{--}$instead of $\mathrm{NO}^{*}$ when cofactors are depleted or inhibited, when specific threonine residues are dephosphorylated or critical cysteines are oxidized [51-54]. 
Defects in the ROS detoxifying machinery can also significantly contribute to the generation of oxidative stress. In some cases of familial amyotrophic lateral sclerosis, mutations of SOD1 enhance its ability to dismutate $\mathrm{H}_{2} \mathrm{O}_{2}$ to ${ }^{\circ} \mathrm{OH}$ and to catalyze tyrosine nitration (Figure 1) [55,56]. Decreased expression of or mutations in catalase lead to oxidative stress in cancer and diabetes [57-59]. Apart from these enzymatic mechanisms for increased ROS production, non-enzymatic pathways are known. In Alzheimer's and Parkinson's disease intracellular accumulation of metals, like copper, iron and manganese leads to enhanced oxidative stress by catalyzing the Fenton reaction or by oxidizing dopamine, which results in ROS production [60]. Furthermore, exposure to toxic chemicals, such as cigarette smoke, can induce oxidative stress.

Importantly, there is extensive cross-talk between the different ROS-generating pathways, driving a vicious cycle of ever increasing cellular oxidative stress. Mitochondrial ROS can, for example, stimulate NOX-mediated ROS production via a PKCdependent pathway and vice versa $[61,62]$. This interplay can potentially drive nuclear ROS production in the context of mitochondrial dysfunction. Moreover, increased mitochondrial ROS inhibit GAPDH through cysteine oxidation [63], causing an increase in all upstream glycolytic products. Under conditions of hyperglycemia (diabetes), this activates alternative arms of glucose metabolism, including the polyol and hexosamine pathways, which contribute to increased ROS formation (Figure 1) [4]. Also, COX is activated by ROS and is itself a source of ROS (Figure 1) [64].

\section{Pathophysiological consequences of oxidative stress}

An important pathogenic mechanism of oxidative stress in neurodegenerative diseases and diabetes is the induction of cell death [65-68]. ROS can participate in cancer development and progression by inducing DNA damage, which leads to mutagenesis, and by affecting the expression of oncogenes [69-71]. In diabetes, oxidative stress causes alterations in the cellular metabolism, contributing to the development of hyperglycemia-associated complications [4,5,63]. Moreover, ROS/RNS-protein and -DNA adducts can function as autoantigens in autoimmune disorders like systemic lupus erythematosus (SLE) [72,73]. In hypertension, reaction of ROS with $\mathrm{NO}^{*}$ is a major pathogenic mechanism inhibiting vasodilation by $\mathrm{NO}^{-}$and generating the damaging $\mathrm{ONOO}^{-}{ }^{[74]}$. Major aspects of the ROS-dependent pathogenic mechanisms are mediated by affecting chromatin components.

\section{Effects of oxidative stress on global chromatin structure}

The global structure of chromatin is strictly organized within a cell. Based on different transcriptional activities, specific sets of chromatin modifications, associated proteins and distinct replication timings in $S$ phase, at least four different chromatin states can be distinguished. These are transcriptionally active euchromatin and three distinct heterochromatic states: transcriptionally repressed chromatin, silent 'null' chromatin, which is not associated with specific proteins or histone marks, and HP1-associated heterochromatin [75]. Maintaining appropriate levels of the latter is important to facilitate genome stability $[76,77]$, proper transcription [78,79], mitosis [80] and meiosis [81]. Oxidative stress can stimulate global heterochromatin loss and thus potentially affect these processes [82].

In this context, it has recently been shown that overexpression of tau, one of the pathogenic factors in Alzheimer's disease, causes oxidative stress-induced heterochromatin loss and neurotoxicity in a Drosophila model [83]. Mechanistically, it was hypothesized that oxidative stress-induced DNA damage promotes chromatin relaxation and thus a global reduction in heterochromatin in neurons. Heterochromatin loss then facilitates ectopic expression of normally silenced genes to induce cell cycle entry of postmitotic neurons [83], which is known to be neurotoxic [84]. In line with these findings, heterochromatin was reduced in neurons isolated from human postmortem Alzheimer's brains and expression of heterochromatic, pluripotency-associated genes was increased [83].

Different mechanisms are in place to protect cells from heterochromatin loss and enhance genome stability upon exposure to oxidative stress. 293F cells, for example, show an increase in the stability of pericentromeric heterochromatin upon exposure to hydrogen peroxide. Pericentromeric heterochromatin is characterized by high levels of the histone $\mathrm{H} 3 \mathrm{~K} 9$ methyltransferase SUV39H1, the SIRT1 deacetylase and HP1 proteins. Hydrogen peroxide upregulates the expression of SIRT1, which increases SUV39H1 stability by inhibiting its ubiquitination and proteasomal degradation. Increased SUV39H1 stability is directly linked to its enhanced turnover at pericentromeric heterochromatin, which decreases DNA damage in response to stress [85]. This mechanism might play a role in the enhanced resistance of cancer cells to oxidative stress and it could possibly be exploited to inhibit heterochromatin loss in neuronal cells, ultimately preventing cell death.

Direct effects of oxidative stress on histones Histones are extensively modified in an ROS- and RNS-dependent way and are glutathionylated in a 
redox-sensitive manner, which affects their folding and stability, as well as their ability to be post-translationally modified. Because histones are the most common chromatin proteins, any change in their abundance, structure or post-translational modifications (PTMs) will have a severe impact on the global structure of chromatin, influencing gene expression, genome stability and replication.

\section{Modification of histones by peroxynitrite}

Histones can be directly modified by peroxynitrite. In vitro exposure of recombinant histones $\mathrm{H} 1$ and $\mathrm{H} 3$ to peroxynitrite leads to tyrosine nitration. Nitrated histones show an increase in structured domains, specifically $\beta$-sheet structures, and increased thermostability. This observed increased thermostability might contribute to protecting DNA from oxidative dam- age during oxidative stress (Figure 2A) [86,87]. Further, nitrated $\mathrm{H} 1$ is a potent autoantigen in SLE and thus contributes to the pathogenesis of this disease [87].

\section{Modification of histones by reactive aldehydes}

Reactive aldehydes are generated intracellularly in an ROS-dependent way. They readily react with proteins to form carbonyl adducts. Lipids can be enzymatically or non-enzymatically peroxidized to yield highly reactive $\alpha, \beta$-unsaturated aldehydes, such as glyoxal, malondialdehyde, acrolein, 4-hydroxy-2-nonenal (4-HNE) or 4-oxo-2-nonenal (4-ONE) [88]. Furthermore, ROS promote the production of the glucose metabolites methylglyoxal and 3-deoxyglucosone [89,90]. These reactive carbonyl species form adducts with permissive cysteines, arginines, lysines or histidines in proteins resulting in advanced glycation endproducts (AGEs)

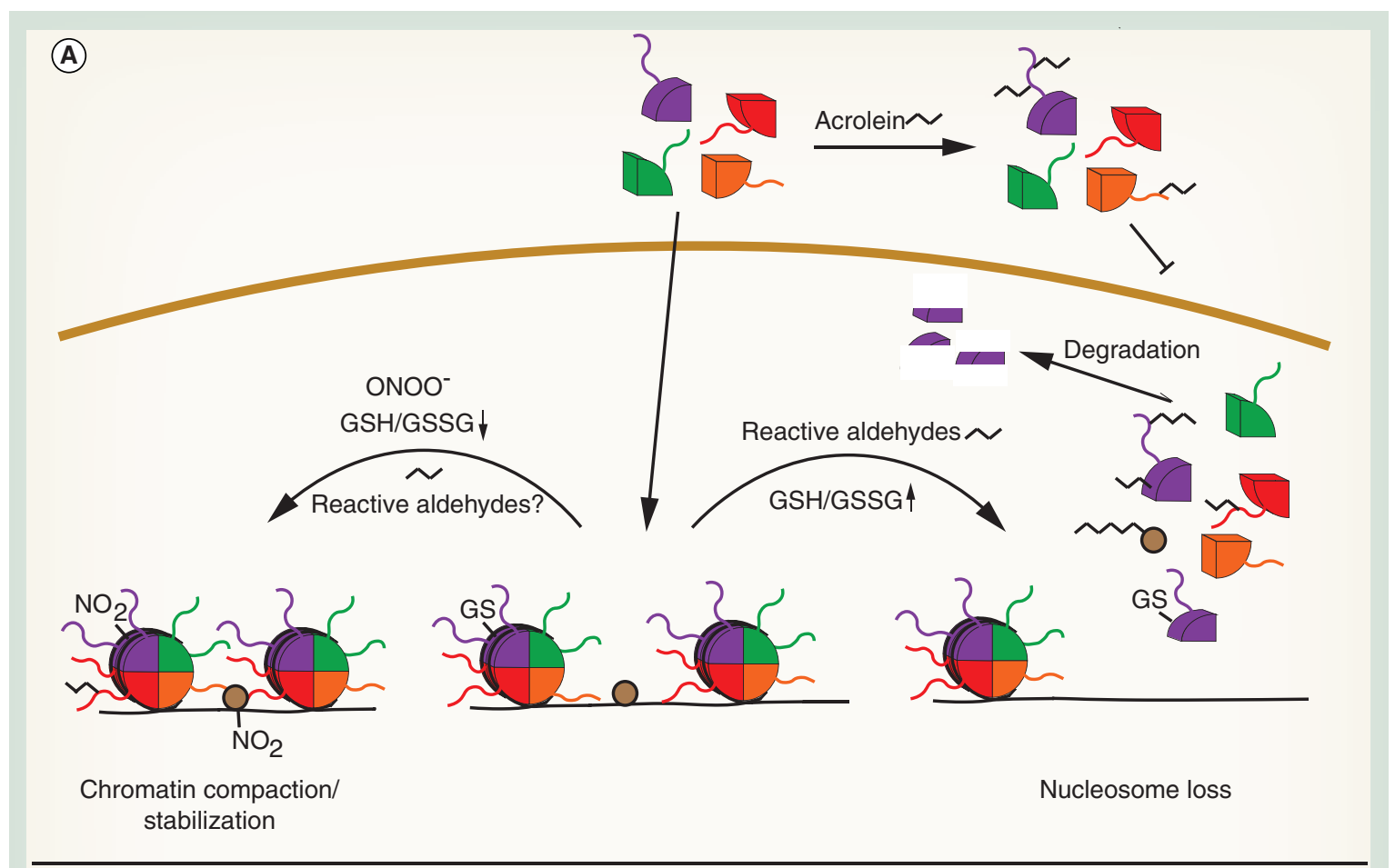

(B)

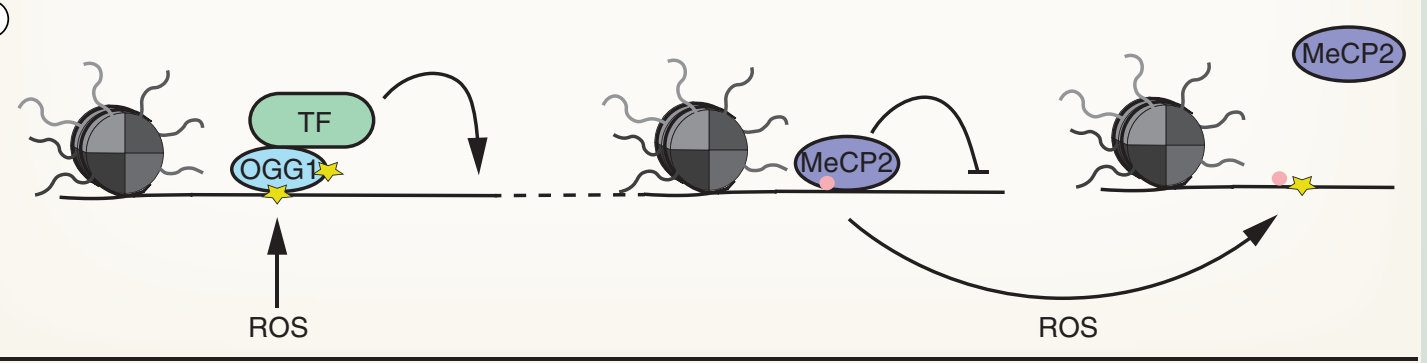

Figure 2. Oxidative stress induces direct modifications of chromatin. (A) Different oxidative histone modifications lead to alterations of chromatin structure. (B) Oxidation of deoxyguanine directly influences gene expression. GS: Reduced glutathione; GSH: Glutathione; GSSG: Glutathione disulfide; NO: Nitric oxide; ROS: Reactive oxygen species; TF: Transcription factor. 
or advanced lipoxidation endproducts and facilitating protein cross-linking [91]. AGEs can further form under conditions of hyperglycemia through direct adduction of glucose or other sugars to proteins and ROS-dependent conversion to carboxymethyllysine or pentosidine $[92,93]$. Strong evidence indicates that carbonylated proteins are implicated in the initiation and progression of human pathologies. Accumulation of AGEs is, for example, associated with increased vascular stiffness in diabetic individuals, both in the macro- and microcirculation [94]. Increases in AGEs have also been described in Alzheimer's disease, where they might contribute to amyloid $\beta$ crosslinking [95].

Histones are common AGEs/advanced lipoxidation endproducts and $\mathrm{H} 2 \mathrm{~A}$ modified by $4-\mathrm{HNE}$ has been identified as an autoantigen in SLE [96]. In vitro, histones $\mathrm{H} 1, \mathrm{H} 2 \mathrm{~A}$ and $\mathrm{H} 3$ that have been modified with 3-deoxyglucosone become less thermostable due to partial unfolding. In vivo, this might lead to alterations in chromatin structure and gene expression [97-99]. In contrast, in vitro glycation of H2A by methylglyoxal led to an increase in alpha-helical structures and stabilization of the protein [100]. These discrepancies might be due to different target residues of the different reactive aldehydes or to the formation of different endproducts.

Several studies indicate that carbonylated histones are lost from chromatin, resulting in an overall reduction in nucleosome content. For example, H1 isolated from livers of diabetic rats displayed a reduced $\alpha$-helical content and diminished binding to DNA [101], suggesting that the structural alterations described for $\mathrm{H} 1$, $\mathrm{H} 2 \mathrm{~A}$ and $\mathrm{H} 3$ in vitro can generally affect association of histones with DNA (Figure 2A). Similarly, increased cellular 4-ONE might trigger global nucleosome loss via inhibition of nucleosome assembly (Figure 2A). In contrast to 4-HNE, which targets a variety of cellular proteins, 4-ONE preferentially modifies histones. Among others, adducts are formed with $\mathrm{H} 3 \mathrm{~K} 23$, $\mathrm{H} 3 \mathrm{~K} 27$ and H4K79, inhibiting nucleosome assembly in vitro. The H3K27 adduct was also detected in LPS-stimulated macrophages, indicating that it might be a novel ROS-mediated, specific histone mark that stimulates transcription, rather than an unspecific, damaging adduct [102].

Another study in human bronchial epithelial cells described a different mechanism for global histone loss. Free histones are more sensitive to adduct formation with the cigarette smoke component acrolein than histones in nucleosomes. Because acrolein reacts with lysine and arginine residues, acetylation of newly synthesized histones was blocked, inhibiting their nuclear import and incorporation into chromatin (Figure 2A). Consistently, high concentrations of acrolein led to a global reduction of chromatin-associated $\mathrm{H} 3$, which correlated with increased transcription at histonedepleted loci [103]. Moreover, glycated histones are irreversibly damaged and need to be removed by the nuclear proteasome [104], which possibly contributes to the global loss of histones from chromatin (Figure 2A).

\section{Glutathionylation of histones}

Glutathionylation is a common modification of proteins in oxidatively stressed cells. Cysteines oxidized to sulfenic acid can be glutathionylated by glutathioneS-transferases (GSTs), utilizing GSH, to protect the residues from further, irreversible oxidation to sulfonic acid $\left(\mathrm{SO}_{3} \mathrm{H}\right)$ [105,106]. However, oxidative stress also increases the oxidation of GSH to GSSG, decreasing the GSH/GSSG ratio. Glutathionylation of histones $\mathrm{H} 3$ and $\mathrm{H} 2 \mathrm{~B}$ has been shown in MCF7 breast cancer cells and is most likely dependent on GSTP1-1. Enhanced glutathionylation correlated with higher GSH levels and drug resistance, suggesting that it might lead to altered expression of drug resistance genes [107].

In agreement with these findings, histone $\mathrm{H} 3$ is glutathionylated in proliferating cells, which is stimulated when the GSH/GSSG ratio is high, but decreases when GSH is depleted (Figure 2A). Glutathionylation of $\mathrm{H} 3$ decreases nucleosome stability, facilitates gene expression and DNA replication [108]. It is conceivable that an oxidative stress-induced reduction in glutathionylation may protect cells from oxidative stress by leading to chromatin compaction and inhibition of replication of potentially damaged DNA. Further, reduced histone glutathionylation might contribute to global gene regulation.

\section{Oxidative damage to DNA}

In addition to histones, DNA can also be directly affected by oxidative stress. The most susceptible nucleoside toward oxidation is deoxyguanosine (dG), which becomes easily oxidized to 8 -oxo-dG. It is normally bound and excised by OGG1 and then repaired by the base excision repair pathway. Recent studies indicate that this oxidatively 'damaged' base can contribute to gene regulation upon oxidative stress.

G-quadruplex (G4) structures, which occur in certain G-rich DNA sequences and consist of guanine tetrads stabilized by hydrogen bonds and monovalent cations, are preferred targets for oxidation. Many oncogenes, like $M Y C, K R A S, V E G F, B C L 2, R B 1$ or HIF1 are regulated by these G4 structures. Some transcription factors do preferentially bind to these sequences and alter the G4 conformational state to regulate gene expression [109]. Hypoxic stress, which leads to enhanced ROS formation, triggers oxidative damage 
preferentially in G4-containing regions and about $25 \%$ of genes regulated by hypoxia contain G4 structures [110]. This might drive the preferential expression of the aforementioned oncogenes. In another study, a mechanism for 8-oxo-dG-induced transcription has been described. Treatment of airway epithelial cells with TNF $\alpha$ leads to enhanced ROS production and an increase in global 8-oxo-dG. OGG1 is also oxidized under these conditions, rendering it enzymatically inactive. Inactive OGG1 does, however, still bind 8-oxo-dG, recruiting transcription factors and enhancing gene expression (Figure 2B) [111].

Oxidative DNA damage can also inhibit binding of chromatin proteins. Methyl-CpG-binding proteins normally recognize methylated $\mathrm{CpG}$ dinucleotides and mediate transcriptional repression. However, binding of methyl-CpG-binding protein 2 to methylated $\mathrm{CpG}$ is inhibited when the guanosine in such a dinucleotide is oxidized or when methylcytosine is oxidatively converted to hydroxymethylcytosine (Figure 2B) [112].

\section{Effects of oxidative stress on DNA methylation}

In addition to directly modifying DNA, ROS can also affect DNA methylation, which is generally linked to repression of transcription. In mammals, the primary methylation targets are cytosines in $\mathrm{CpG}$ dinucleotides. While $\mathrm{CpGs}$ are usually methylated genomewide, regions with a high density of $\mathrm{CpG}$ dinucleotides (CpG islands) are mostly hypomethylated [113]. Two classes of enzymes control DNA methylation: DNMTs and the demethylases of the TET family. DNMTs utilize $S$-adenosylmethionine (SAM) to transfer a methyl group to cytosine, while TETs oxidize 5-methylcytosine $(5-\mathrm{mC})$ to 5 -hydroxymethylcytosine $(5-\mathrm{hmC})$ in an $\mathrm{Fe}(\mathrm{II})-, \quad \alpha$-ketoglutarate- $(\alpha-\mathrm{KG})$, ascorbate- and $\mathrm{O}_{2}$-dependent reaction $[114,115]$.

In many pathologies, like Alzheimer's disease, diabetes or cancer global DNA hypomethylation has been described [116-119]. However, some specific CpG islands are hypermethylated in diabetes or cancer $[117,120]$ and it has been suggested that both global hypomethylation and specific hypermethylation can be linked to oxidative stress.

DNA methylation is directly blocked when SAM decreases. SAM is synthesized from methionine by methionine adenosyltransferase (MAT). It is then used for methylation reactions, producing $S$-adenosylhomocysteine, which is hydrolyzed to homocysteine. Methionine is regenerated from homocysteine by methionine synthase (MS) (Figure 3). Depletion of SAM can be triggered by oxidative stress via several mechanisms. Firstly, oxidation of MAT leads to its inactivation and to reduced SAM synthesis from methionine [121,122].
Secondly, the cobalamine in MS is easily oxidized, which leads to inactivation of the enzyme. MS can be reactivated by MS reductase utilizing SAM, forming a futile cycle without any net SAM production [123]. And thirdly, the transsulfuration pathway can regenerate glutathione under oxidative stress conditions from SAM via homocysteine, cystathionine and cysteine, depleting SAM in the process (Figure 3) [124-126]. In agreement with this, SAM and DNA methylation were decreased in oxidatively stressed bladder cancer and kidney cell lines. There, supplying SAM, methionine or $N$-acetylcysteine restored DNA methylation [127]. Similarly, 5-mC levels in liver tissue of hamsters treated with the GSH-depleting agent bromobenzene were reduced. This hypomethylation was rescued, when the animals were supplied with methionine [128]. Both experiments indicate that a reduction in SAM, and not oxidation or modification of DNMTs, was the prime reason for reduced DNA methylation. However, direct oxidation of $5-\mathrm{mC}$ to $5-\mathrm{hmC}$ can also lead to DNA demethylation. 5-hmC inhibits maintenance methyltransferase DNMT1, thus blocking the proper inheritance of methylation patterns and leading to indirect demethylation of CpG sites [129].

A mechanism for DNA hypermethylation upon oxidative stress is the inhibition of TET proteins. As $\mathrm{Fe}(\mathrm{II})$ - and $\alpha$-KG-dependent dioxygenases, they can be inactivated by iron oxidation. During the catalytic cycle, $\mathrm{Fe}(\mathrm{II})$ is oxidized to $\mathrm{Fe}$ (III) and $\mathrm{Fe}$ (IV) [115] and it was hypothesized that oxidized iron is regenerated by ascorbate [114]. Under oxidative stress conditions, this regeneration is perturbed, leading to inactivation of the enzyme and an increase in global 5-mC levels [130]. Consistent with this, $5-\mathrm{hmC}$ is significantly reduced in oxidatively stressed SY5Y neuroblastoma cells [131]. Furthermore, TET1 knockdown enhances cell death in murine cerebellar granule cells, indicating that TET1 inhibition by oxidative stress could be involved in the pathogenesis of neurodegenerative diseases [132]. Additionally, the Krebs cycle intermediates succinate and fumarate inhibit TETs competitively due to their similarity with $\alpha-\mathrm{KG}$ [133]. This mechanism might play a role in hyperglycemia, which leads to an increase in fumarate due to impairments in the mitochondrial electron transport chain [134]. An increase in succinate can result from the inhibition of succinate dehydrogenase by oxidative stress (Figure 3) [135].

Both hypermethylation of $\mathrm{CpG}$ islands and global hypomethylation can also be mediated by relocalization of DNMTs. Base excision and mismatch repair proteins recognize 8-oxo-dG and recruit maintenance DNA methyltransferase DNMT1, which forms a complex with the SIRT1 deacetylase, the de novo DNA methyltransferase DNMT3B and the histone 


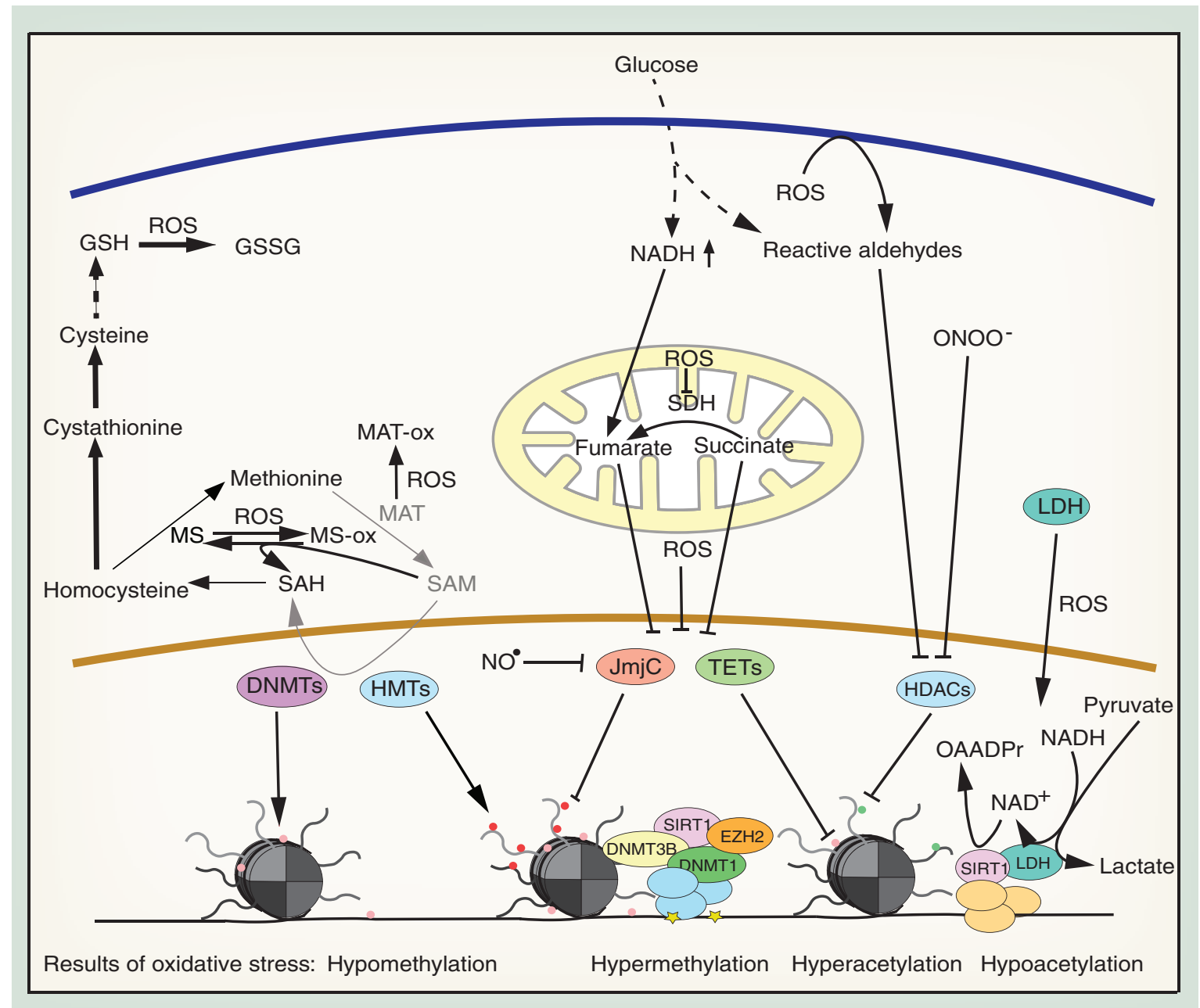

Figure 3. Oxidative stress influences chromatin modifiers. Chromatin modifying enzymes can be inhibited under oxidative stress conditions by different mechanisms, including SAM depletion, oxidation, carbonylation or nitration. Activation of DNA methylation is mediated by oxidative DNA damage and the SIRT1 HDAC can be stimulated by LDH.

DNMT: DNA methyltransferase; GSH: Glutathione; HDAC: Histone deacetylase; HMT: Histone methyltransferase; LDH: Lactate dehydrogenase; MAT: Methionine adenosyltransferase; MS: Methionine synthase;

NAD+: Nicotinamide adenine dinucleotide; NO: Nitric oxide; ROS: Reactive oxygen species;

SAM: S-adenosylmethionine; TET: Ten-Eleven-Translocation DNA demethylase.

H3K27 methyltransferase EZH2 [136,137]. The complex is mainly recruited to active $\mathrm{CpG}$ island promoter regions, where increased 8-oxo-dG is present, and it enhances DNA methylation and H3K27me3, while reducing $\mathrm{H} 3 \mathrm{~K} 4 \mathrm{me} 3$ and $\mathrm{H} 4 \mathrm{~K} 16 \mathrm{ac}$ levels (Figure 3). Simultaneously, DNMT1, DNMT3B and SIRT1 are lost from other genomic regions. As a consequence, $\mathrm{CpG}$ islands of lowly expressed genes were hypermethylated in an in vivo mouse colitis model after exposure to oxidative stress, while housekeeping genes remained unaffected. These same genes have also been shown to be hypermethylated in intestinal cancer, providing a mechanistic explanation for how oxidative stress can drive cancer-specific gene expression [136].

\section{Effects of oxidative stress on histone modifications}

Histone PTMs provide an additional layer of complexity for the regulation of chromatin structure and chromatin-regulated processes beyond the simple structural properties of histones. Covalent histone PTMs can directly or through the recognition by chromatin reader proteins influence transcription, chromatin structure, DNA repair or mitosis. Chromatin reader proteins are, for example, adaptor proteins or different enzymes, like chromatin modifiers or chromatin remodeling complexes [13]. Oxidative stress influences histone PTMs in various ways and thus affects a number of chromatin-regulated processes. 
Histone lysine methylation

Lysines can be mono-, di- or trimethylated and histone lysine methylation is controlled by HMTs and HDMs. The latter can be divided into LSD and JmjC family enzymes. LSD enzymes catalyze demethylation of mono- and dimethylated lysines, JmjC proteins target all methylation states [138]. Especially JmjC family proteins can be inhibited by oxidative stress, leading to histone hypermethylation. The best-studied methylation marks are $\mathrm{H} 3 \mathrm{~K} 4 \mathrm{me} 1 / 2 / 3, \mathrm{H} 3 \mathrm{~K} 9 \mathrm{me} 2 / 3$ and $\mathrm{H} 3 \mathrm{~K} 27 \mathrm{me} 3$. H3K4 methylation is generally associated with transcriptional activation, $\mathrm{H} 3 \mathrm{~K} 9 \mathrm{me} 2 / 3$ are mainly found in constitutive heterochromatin and are associated with heterochromatin formation and maintenance, and $\mathrm{H} 3 \mathrm{~K} 27 \mathrm{me} 3$ is associated with transcriptional silencing and facultative heterochromatin [13]. Alterations in these methylation marks can therefore result in aberrant transcription or changes in chromatin packaging.

Like DNA demethylases of the TET family, HDMs of the JmjC family are $\mathrm{Fe}$ (II)- and $\alpha$-KG-dependent dioxygenases. As such, they are also inhibited by high levels of fumarate, which led to a global increase in H3K4me1, H3K4me3, H3K9me2/3 H3K27me2/3 and $\mathrm{H} 3 \mathrm{~K} 79 \mathrm{me} 2$ in fumarate hydratase deficient cells $[133,139]$. Further, iron oxidation blocks the catalytic activity of JmjC HDMs (Figure 3) and especially $\mathrm{H} 3 \mathrm{~K} 4 \mathrm{me} 3$ was significantly increased globally after exposure of human bronchial epithelial cells to hydrogen peroxide [130].

JmjC demethylases can also be inhibited by nitrosative stress. The $\mathrm{NO}^{\circ}$ radical inhibits the JmjC domaincontaining demethylase KDM3A by directly binding to the catalytic iron (Figure 3). Consequently, treatment of cells with $\mathrm{NO}^{\circ}$ results in an increase in $\mathrm{H} 3 \mathrm{~K} 9 \mathrm{me} 2$, which is normally targeted by KDM3A. Although NO${ }^{\circ}$ caused a simultaneous upregulation of KDM3A, this did not compensate for the $\mathrm{NO}^{\circ}$-dependent inhibition of the enzyme [140].

Lastly, HMTs could also be affected by oxidative stress. They are dependent on SAM and in oxidatively stressed cells reduced SAM levels are expected to block histone methylation and thus globally alter chromatin structure (Figure 3) [125,141].

It is important to note that oxidative stress does not influence all histone lysine marks in the same way. While some residues are hypermethylated in response to an oxidative insult, others are unaffected or even become hypomethylated [130]. This is intriguing because all known HMTs depend on SAM and all trimethylated residues are exclusively targeted by JmjC family HDMs. The observed specific effects might be a consequence of different enzymes having distinct sensitivities toward oxidation, nitration, competitive inhi- bition or SAM depletion, depending on structural features of the enzyme or on the microenvironment of an enzyme complex. In this context, it has recently been shown that MATII can be recruited to target genes by the H3K9 methyltransferase SETDB1 [142]. This leads to a local increase in SAM and could facilitate histone methylation even in the absence of high global SAM levels. Hence, specific local rather than global regulation of HMT and HDM activities might predominate in vivo.

\section{Histone acetylation}

In contrast to methylation, acetylation of lysine residues neutralizes the positive charge of the histone tail and is therefore generally associated with chromatin relaxation and transcriptional activation. Global changes in histone acetylation patterns do thus have a broad and immediate impact on cell physiology and are intricately linked to several diseases. Histone acetylation is controlled by histone acetyltransferases and histone deacetylases (HDACs). HDACs are grouped into class I, II, III and IV enzymes, depending on their structure, homology to yeast HDACs, subcellular localization and catalytic mechanism [143-145]. Class I, II and VI enzymes possess a catalytic metal ion and produce free acetate [146], while class III HDACs or sirtuins require a structural zinc ion and $\mathrm{NAD}^{+}$, to which they transfer the acetyl group producing O-acetyl-ADP-ribose [147-149].

Oxidative and nitrosative stress are potent modulators of HDAC function at multiple levels. It has been shown that most class I HDACs (HDAC1, HDAC2 and HDAC3) are alkylated and inhibited by several reactive aldehydes, which results in changes in gene expression [150,151]. Moreover, HDAC2 can be nitrosylated [152], the effect of which is being discussed controversially. In one study conducted in neurons, nitrosylation did not influence its activity, but led to displacement from chromatin to activate gene expression [153]. In another study in C2C12 myoblasts, cysteine nitrosylation decreased HDAC2 activity [154]. In this context, it is interesting to note that knockdown or knockout of HDAC1, HDAC2 or HDAC3 can promote the development of hematological malignancies and hepatocellular carcinoma [155-158], indicating that ROS-mediated HDAC inhibition is potentially oncogenic. Furthermore, inhibition of HDACs by oxidative stress might be a physiological response to confer oxidative stress resistance to cells. Treatment of mice with the HDAC inhibitor $\beta$-hydroxybutyrate led to upregulation of FOXO3A and metallothioneine 2, two proteins that protect cells from oxidative stress [159].

Several class III HDACs are also inhibited by oxidative stress. SIRT1 can be inactivated as a result of 
cysteine carbonylation [160], nitrosylation [152] or glutathionylation [161]. Inactivation of SIRT1 during oxidative stress leads to increased acetylation and inhibition of FOXO3. Activation or overexpression of SIRT1, in contrast, protects cells from oxidative stress-induced senescence [162,163], indicating that SIRT1 inhibition negatively affects oxidatively stressed cells. Inactivation of SIRT1 by cigarette smoke results in enhanced acetylation of NFK-B and the increased expression of proinflammatory genes in macrophages [164]. Similarly, SIRT3 has been shown to be carbonylated and inactivated by 4 -HNE [165]. Nuclear SIRT3 is rapidly degraded when cells are exposed to oxidative stress, leading to the upregulation of stress-induced genes [166]. Moreover, the tumor suppressor SIRT6 can be inactivated through peroxynitrite-mediated nitrosylation [167,168], which could be oncogenic.

A different mechanism of oxidative stress regulation has been described for class II HDACs. In cardiac myocytes HDAC4 and HDAC5 translocate from the nucleus to the cytoplasm in an ROS-dependent manner [169]. This process stimulates transcription of MEF2-dependent genes, which has been shown to trigger hypertrophic growth of cardiac myocytes [170].

Although ROS are potent inhibitors of HDACs they can also increase histone deacetylation by directly stimulating HDAC expression $[171,172]$ or by indirectly enhancing HDAC activity. Treatment of HepG2 cells with $\mathrm{H}_{2} \mathrm{O}_{2}$ led to an increase in nuclear lactate dehydrogenase, which catalyzes the reduction of pyruvate to lactate using $\mathrm{NADH}$ and producing $\mathrm{NAD}^{+}$. Lactate dehydrogenase directly interacts with SIRT1 and provides the enzyme with $\mathrm{NAD}^{+}$to stimulate deacetylation [173].

\section{Histone phosphorylation}

Phosphorylation of different histone serine, threonine and tyrosine residues plays a role in the regulation of gene expression, DNA repair and mitosis [174]. Several studies show that oxidative stress can indirectly influence global histone phosphorylation levels. Oxidative stress leads to the formation of DNA double-strand breaks, which induce the phosphorylation of H2AX to trigger DNA repair [175,176]. Additionally, one study showed that $\mathrm{H}_{2} \mathrm{O}_{2}$ treatment increases $\mathrm{H} 2 \mathrm{AX}$ phosphorylation in an ATR-dependent way independent of the presence of double-strand breaks, suggesting that it fulfills a different signaling function in oxidatively stressed cells [177]. The effect of ROS on H3S10 phosphorylation is controversial. While oxidative stress increased H3S10p in monocytes and alveolar macrophages in a p38-, MSK1- and IKK2-dependent way [178], it inhibited H3S10 phosphorylation by VRK1 in SY5Y neuroblastoma cells through upregulation of
MKP2 [179]. The histone-targeting protein phosphatases PP1 and PP2A can be inhibited by oxidation of their catalytic metal ion [180]. Whether this is a mechanism by which oxidative stress can directly modulate histone phosphorylation levels needs, however, to be seen.

\section{Regulation of chromatin-associated proteins} Regulation of TRIM28

TRIM28 or KAP1 is a global transcriptional corepressor protein. It can be recruited to a number of transcription factors and interacts with HDACs and HMTs [181]. Two mechanisms of negative regulation of TRIM28 by oxidative stress have been described. The first one involves nuclear import of tyrosyl-tRNA synthetase in oxidatively stressed cells, where it sequesters TRIM28 and HDAC1 to facilitate transcriptional activation of DNA damage repair genes. This protects cells from oxidative stress-induced DNA damage (Figure 4A) [182].

The second mechanism involves oxidation HP1 $\gamma$. $\mathrm{HP} 1 \mathrm{~s}$ bind $\mathrm{H} 3 \mathrm{~K} 9 \mathrm{me} 3$ and have conventionally been described as essential proteins for heterochromatin formation and maintenance. They are homodimeric proteins, which interact with a number of other chromatin factors. HP1 $\gamma$ is associated with both eu- and heterochromatin. In euchromatin, it has been shown to regulate gene expression, both positively and negatively. It was recently demonstrated that HP1 $\gamma$ is oxidized upon induction of oxidative stress in cultured cells. Oxidation leads to reversible disulfide bond and covalent homodimer formation. This significantly enhances the interaction of HP1 $\gamma$ with TRIM28, sequestering it and inhibiting its repressive function toward a reporter gene (Figure 4A). Consistent with this, HP1 $\gamma$ is required to retain cell viability after an oxidative stress insult, suggesting that this mechanism also contributes to gene regulation upon oxidative stress [183]. Interestingly, TRIM28 heterozygous mice are obese and show signs of metabolic syndrome, like decreased glucose tolerance [184], indicating that a reduction in TRIM28 levels or availability, for example, by sequestration in oxidatively stressed cells, could be causative for this disease.

\section{Regulation of HMGB1}

HMGBs are structural DNA-binding proteins that can bend, loop or unwind DNA. They can mediate nucleosome remodeling, DNA accessibility and histone H1 displacement to facilitate transcriptional activation. HMGB1 interacts with $\mathrm{H} 1$ through its highly acidic C terminus [185]. The functions of HMGB1 can be regulated by reversible oxidation of the protein, which leads to disulfide bond formation and conformational 


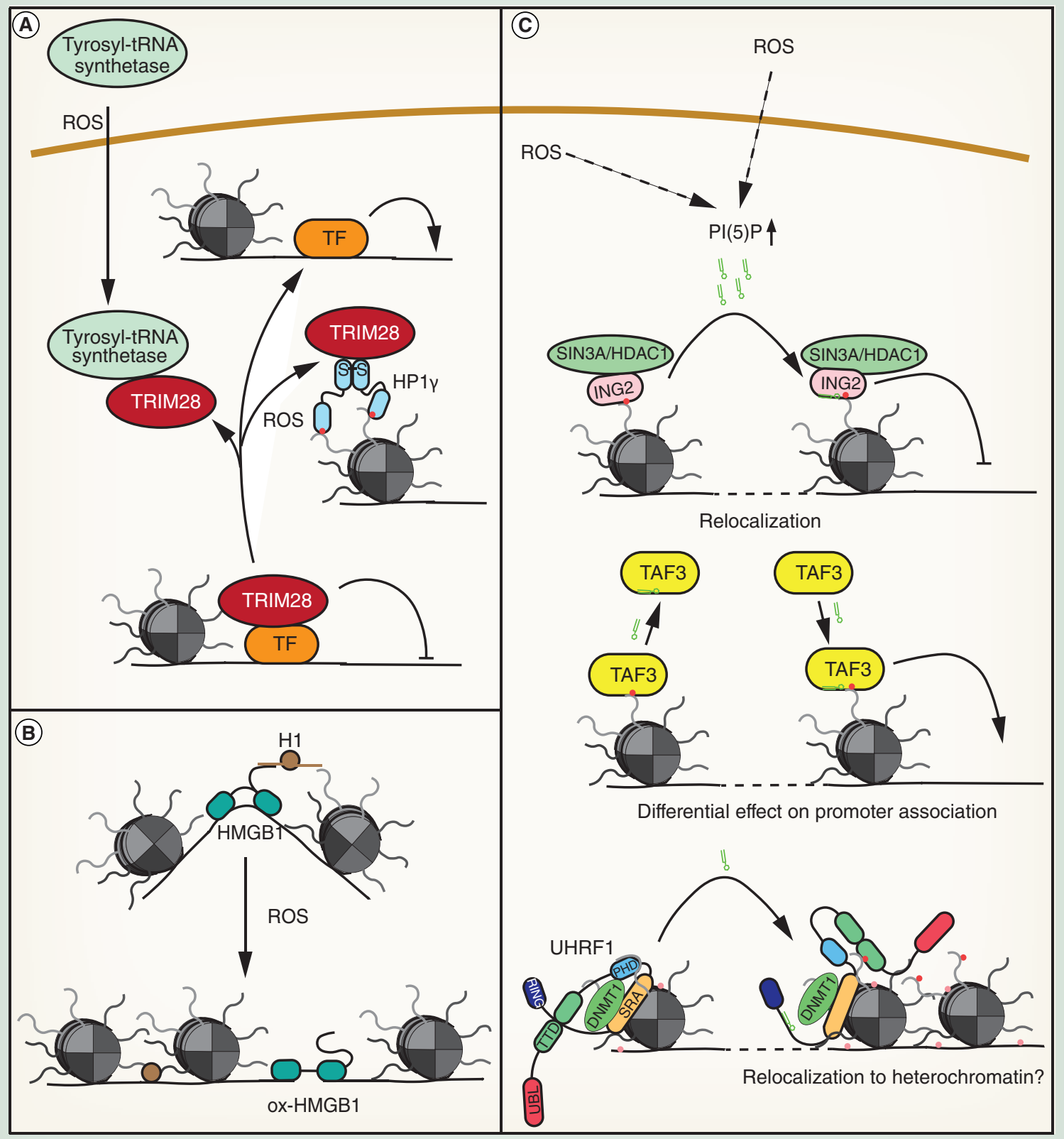

Figure 4. Effects of oxidative stress on different chromatin proteins. (A) Regulation of TRIM28 by oxidative stress. (B) Influence of oxidative stress on functions of HMGB1. (C) Regulation of chromatin proteins by PI(5)P.

PI(5)P: Phosphatidylinositol-5-phosphate; ROS: Reactive oxygen species; TF: Transcription factor.

changes in the DNA-binding and -bending domain. Consistent with this, oxidized HMGB1 shows a twofold lower DNA-binding affinity and loses its ability to bend DNA. It does, however, gain a DNA endjoining function, potentially increasing DNA repair after an oxidative insult. It also shows reduced affinity toward histone $\mathrm{H} 1$ and its ability to displace $\mathrm{H} 1$ from DNA is significantly inhibited (Figure 4B). In response to oxidative stress, stabilization of $\mathrm{H} 1$ on chromatin might repress transcription and enhance chromatin stability [186]. Further, reduced bending of DNA by HMGB1 might result in transcriptional repression through impaired interactions of regulatory elements.

Regulation of chromatin-binding proteins by the second messenger PI(5)P during oxidative stress Phosphatidylinositol phosphates are important second messengers in a number of signal transduction 
pathways. They are present in all cellular membrane compartments and, surprisingly, also in the nuclear matrix. Enzymes that produce mono-, di- and triphosphorylated PI have been detected in the nucleus, suggesting that the nuclear pool can be regulated independently of the membrane pool $[187,188]$. Indeed, recent publications highlight the specific functions of nuclear phosphatidylinositol phosphates as signaling molecules. $\mathrm{PI}(5) \mathrm{P}$ increases in response to $\mathrm{H}_{2} \mathrm{O}_{2}$ and etoposide treatment [189], which mediates its effects by inducing oxidative stress and oxidative stress-dependent DNA damage [190]. PI(5)P might be a general mediator of the oxidative stress response, targeting a number of different chromatin proteins.

PI(5)P binds to ING2 [191], which specifically recognizes H3K4me3 and can associate with the p300 histone acetyltransferases [192] or the SIN3A-HDAC1 complex [193] to stimulate or repress transcription. PI(5)P binding to the ING2 plant homeodomain (PHD) triggers its relocalization to novel chromatin sites and is essential for repression of proproliferative genes [194] and the induction of apoptosis upon etoposide treatment (Figure 4C) [191]. Alterations in the transcriptional program can also be mediated by $\mathrm{PI}(5)$ P-dependent regulation of the general transcription factor TAF3 by either increasing or decreasing binding to promoter elements (Figure 4C) [195].

Another chromatin protein that interacts with PI(5)P is UHRF1. UHRF1 interacts with DNMT1, it is implicated in maintenance DNA methylation and stimulates proliferation in breast, prostate and lung cancer [196]. UHRF1 is composed of five domains, an N-terminal ubiquitin-like domain, an $\mathrm{H} 3 \mathrm{~K} 9$ me3-binding tandem tudor domain (TTD), a PHD, which binds the unmodified N-terminal histone $\mathrm{H} 3$ tail, a hemi-methyl-CpGbinding SRA domain and a C-terminal RING domain. These domains are connected by flexible linkers. PI(5) $P$ binding to the UHRF1 polybasic region in the linker between the SRA and RING domains alters the overall conformation of the protein. While the TTD is blocked in the non-PI(5)P bound protein, enabling binding of the unmodified $\mathrm{H} 3 \mathrm{~N}$-terminus to the PHD only, PI(5)P unblocks the TTD domain, allowing for binding of the TTD to K9me3-modified histone tails (Figure 4C) [197]. This mechanism might protect the genome from oxidative insults by facilitating heterochromatin and DNA methylation maintenance under conditions of oxidative stress. Furthermore, relocalization of UHRF1 to H3K9me3-marked chromatin might alter gene expression programs in stressed cells.

\section{Conclusion \& future perspective}

As we have discussed, oxidative stress globally influences chromatin on multiple levels, from DNA and histones to histone modifiers and structural DNAbinding proteins. Also, it is well known that oxidative stress is involved in initiation and progression of neurodegenerative diseases, diabetes, hypertension, cancer and several other pathologies. Nevertheless, for most mechanisms of chromatin regulation by oxidative stress highlighted in this review, a direct link to diseases has not been demonstrated. By and large, general effects of ROS have been described in different tissue culture model systems. Since the chromatin changes induced by oxidative or nitrosative stress observed there are also seen in human diseases, it can be projected that ROS-mediated chromatin alterations play an important role in initiation and progression of the aforementioned pathologies. Future research needs to focus on directly demonstrating how oxidative stress-induced chromatin changes impact on human diseases. Important questions to address are: how do ROS and RNS affect chromatin in specific cells in a disease setting? What are the molecular mechanisms for the observed oxidative stress-induced chromatin changes? What are the cellular effects of these chromatin changes? And what is the pathogenic potential of these chromatin-mediated effects?

Once these issues are resolved we are confident that it will be possible to exploit oxidative stressmediated chromatin changes in diseases to develop drugs targeting specific ROS-induced chromatin signaling pathways. Antioxidants have already been widely tested as a treatment for neurodegenerative diseases, diabetes and cancer, but results were contradictory, ranging from improvement of the disease to accelerated progression [198-202]. Consistent with this, ROS have both protective and damaging effects on cells. To be effective, it will indeed be important to only target distinct parts of the ROS-dependent response. In this context, chromatin is a very interesting target for drug development because it integrates and mediates most cellular responses to extraand intracellular stimuli. Furthermore, a number of small molecule inhibitors of chromatin modifying enzymes are already in clinical trials or are even being used as successful therapeutics, making them readily available for therapy. We are looking forward to the many basic connections between ROS, chromatin and human pathologies to be made and to their translation into medical applications.

\section{Financial \& competing interests disclosure}

The research reported in this publication was supported by funding from King Abdullah University of Science and Technology (KAUST). The authors have no other relevant affiliations or financial involvement with any organization or entity 
with a financial interest in or financial conflict with the subject matter or materials discussed in the manuscript apart from those disclosed.

No writing assistance was utilized in the production of this manuscript.

\section{Open access}

This work is licensed under the Attribution-NonCommercialNoDerivatives 4.0 Unported License. To view a copy of this license, visit http://creativecommons.org/licenses/by-nc$\mathrm{nd} / 4.0 /$

\section{Executive summary}

\section{Oxidative stress}

- Oxidative stress is an imbalance between oxidants and antioxidants in favor of the oxidants, leading to a disruption of redox signaling and control and/or molecular damage. It is linked to the initiation and progression of several common human diseases.

Oxidative stress \& global chromatin structure

- Depending on the cell type, oxidative stress triggers global heterochromatin loss and cell death or protective stabilization of heterochromatin.

- Direct oxidative modifications of histones alter the global chromatin structure, induce changes in transcription, DNA replication and might regulate cell death.

Oxidative stress \& DNA methylation

- Oxidative stress-induced inhibition of DNA methyltransferases and relocalization of DNA methyltransferases to CpG islands induces global DNA hypomethylation and local promoter hypermethylation.

- Inhibition of Fe(II)- and $\alpha-K G$-dependent TET DNA demethylases by oxidation, fumarate or succinate leads to altered DNA methylation.

Oxidative stress \& histone modifications

- Oxidative stress inhibits Fe(II)- and $\alpha-K G$-dependent histone demethylases of the JmjC family and potentially triggers histone hypermethylation.

- Oxidative stress directly inhibits histone deacetylases, but also stimulates their expression and locally increases NAD+ to activate SIRT deacetylases.

\section{Oxidative stress regulates DNA-associated proteins}

- The corepressor TRIM28 is sequestered from the chromatin under conditions of oxidative stress by binding to tyrosyl-tRNA synthetase or oxidized HP1 $\gamma$, leading to activation of gene expression.

- Oxidized HMGB1 loses its DNA-bending activity and its ability to displace histone H1, possibly inhibiting gene expression and stabilizing chromatin. At the same time, it gains a DNA end-joining function, likely contributing to DNA repair after an oxidative insult.

- The second messenger PI(5)P is upregulated by oxidative stress and modulates the functions of the corepressor ING2, the general transcription factor TAF3 and the structural chromatin protein UHRF1, thus controlling transcription at multiple levels.

Future perspective

- Oxidative stress widely affects chromatin and is implicated in several human diseases. Further studies are required to comprehend the exact molecular connections of these phenomena for exploiting the management of oxidative stress-induced alterations for therapeutic purposes.

\section{References}

Papers of special note have been highlighted as:

- of interest; $\bullet \bullet$ of considerable interest

1 Chen Z, Zhong C. Oxidative stress in Alzheimer's disease. Neurosci. Bull. 30(2), 271-281 (2014).

2 Yan MH, Wang X, Zhu X. Mitochondrial defects and oxidative stress in Alzheimer disease and Parkinson disease. Free Radic. Biol. Med. 62, 90-101 (2013).

3 Poon HF, Hensley K, Thongboonkerd V et al. Redox proteomics analysis of oxidatively modified proteins in G93A-SOD1 transgenic mice - a model of familial amyotrophic lateral sclerosis. Free Radic. Biol. Med. 39(4), 453-462 (2005).

4 Yan L-J. Pathogenesis of chronic hyperglycemia: from reductive stress to oxidative stress. J. Diabetes Res. 2014, 137919 (2014).
5 Giacco F, Brownlee M. Oxidative stress and diabetic complications. Circ. Res. 107(9), 1058-1070 (2010).

6 Madamanchi NR, Vendrov A, Runge MS. Oxidative stress and vascular disease. Arterioscler. Thromb. Vasc. Biol. 25(1), 29-38 (2005).

7 Hernanz R, Briones AM, Salaices M, Alonso MJ. New roles for old pathways? A circuitous relationship between reactive oxygen species and cyclo-oxygenase in hypertension. Clin. Sci. 126(2), 111-121 (2014).

8 Perl A. Oxidative stress in the pathology and treatment of systemic lupus erythematosus. Nat. Rev. Rheumatol. 9(11), 674-686 (2013).

9 Block K, Gorin Y. Aiding and abetting roles of NOX oxidases in cellular transformation. Nat. Rev. Cancer 12(9), 627-637 (2012). 
10 Sabharwal SS, Schumacker PT. Mitochondrial ROS in cancer: initiators, amplifiers or an Achilles' heel? Nat. Rev. Cancer 14(11), 709-721 (2014).

11 Badeaux AI, Shi Y. Emerging roles for chromatin as a signal integration and storage platform. Nat. Rev. Mol. Cell Biol. 14(4), 211-224 (2013).

12 Schübeler D. Function and information content of DNA methylation. Nature 517(7534), 321-326 (2015).

13 Bannister AJ, Kouzarides T. Regulation of chromatin by histone modifications. Cell Res. 21(3), 381-395 (2011).

14 Sies H, Jones D. Oxidative Stress. In: Encyclopedia of Stress (Second Edition). Fink G (Ed.). Academic Press, New York, USA, 45-48 (2007).

15 Kojer K, Riemer J. Balancing oxidative protein folding: the influences of reducing pathways on disulfide bond formation. Biochim. Biophys. Acta 1844(8), 1383-1390 (2014).

16 López-Mirabal HR, Winther JR. Redox characteristics of the eukaryotic cytosol. Biochim. Biophys. Acta 1783(4), 629-640 (2008).

17 Espinosa-Diez C, Miguel V, Mennerich D et al. Antioxidant responses and cellular adjustments to oxidative stress. Redox Biol. 6, 183-197 (2015).

18 Pisoschi AM, Pop A. The role of antioxidants in the chemistry of oxidative stress: a review. Eur. J. Med. Chem. 97, 55-74 (2015).

19 Go Y-M, Jones DP. Redox control systems in the nucleus: mechanisms and functions. Antioxid. Redox Signal. 13(4), 489-509 (2010).

20 Kowaltowski AJ, de Souza-Pinto NC, Castilho RF, Vercesi AE. Mitochondria and reactive oxygen species. Free Radic. Biol. Med. 47(4), 333-343 (2009).

21 Tretter L, Adam-Vizi V. Alpha-ketoglutarate dehydrogenase: a target and generator of oxidative stress. Philos. Trans. R. Soc. B Biol. Sci. 360(1464), 2335-2345 (2005).

22 Murphy MP. How mitochondria produce reactive oxygen species. Biochem. J. 417(Pt 1), 1-13 (2009).

23 St-Pierre J, Buckingham JA, Roebuck SJ, Brand MD. Topology of superoxide production from different sites in the mitochondrial electron transport chain. J. Biol. Chem. 277(47), 44784-44790 (2002).

24 Lambeth JD. NOX enzymes and the biology of reactive oxygen. Nat. Rev. Immunol. 4(3), 181-189 (2004).

25 Radi R. Peroxynitrite, a stealthy biological oxidant. J. Biol. Chem. 288(37), 26464-26472 (2013).

26 Petry A, Weitnauer M, Görlach A. Receptor activation of NADPH oxidases. Antioxid. Redox Signal. 13(4), 467-487 (2009).

27 Matsushima S, Kuroda J, Ago T et al. Increased oxidative stress in the nucleus caused by Nox4 mediates oxidation of HDAC4 and cardiac hypertrophy. Circ. Res. 112(4), 651-663 (2013).

28 Schieber M, Chandel NS. ROS function in redox signaling and oxidative stress. Curr. Biol. 24(10), R453-R462 (2014).

29 Reczek CR, Chandel NS. ROS-dependent signal transduction. Curr. Opin. Cell Biol. 33, 8-13 (2015).
30 Meng T-C, Fukada T, Tonks NK. Reversible oxidation and inactivation of protein tyrosine phosphatases in vivo. Mol. Cell 9(2), 387-399 (2002)

31 Lee S-R, Yang K-S, Kwon J, Lee C, Jeong W, Rhee SG. Reversible inactivation of the tumor suppressor PTEN by H2O2. J. Biol. Chem. 277(23), 20336-20342 (2002).

32 Kamata H, Honda S, Maeda S, Chang L, Hirata H, Karin M. Reactive oxygen species promote TNF $\alpha$-induced death and sustained JNK activation by inhibiting MAP kinase phosphatases. Cell 120(5), 649-661 (2005).

33 Nadeau PJ, Charette SJ, Toledano MB, Landry J. Disulfide bond-mediated multimerization of Ask1 and its reduction by thioredoxin-1 regulate $\mathrm{H} 2 \mathrm{O} 2$-induced c-Jun NH2-terminal kinase activation and apoptosis. Mol. Biol. Cell 18(10), 3903-3913 (2007).

34 Marinho HS, Real C, Cyrne L, Soares H, Antunes F. Hydrogen peroxide sensing, signaling and regulation of transcription factors. Redox Biol. 2, 535-562 (2014).

35 Nelson KK, Melendez JA. Mitochondrial redox control of matrix metalloproteinases. Free Radic. Biol. Med. 37(6), 768-784 (2004)

36 Provost C, Choufani F, Avedanian L, Bkaily G, Gobeil F, Jacques D. Nitric oxide and reactive oxygen species in the nucleus revisited. Can. J. Physiol. Pharmacol. 88(3), 296-304 (2010).

37 Saluja R, Jyoti A, Chatterjee $\mathrm{M}$ et al. Molecular and biochemical characterization of nitric oxide synthase isoforms and their intracellular distribution in human peripheral blood mononuclear cells. Biochim. Biophys. Acta 1813(10), 1700-1707 (2011).

38 Stuehr DJ, Santolini J, Wang Z-Q, Wei C-C, Adak S. Update on mechanism and catalytic regulation in the NO synthases. J. Biol. Chem. 279(35), 36167-36170 (2004).

39 Hill BG, Dranka BP, Bailey SM, Lancaster JR, DarleyUsmar VM. What part of NO don't you understand? Some answers to the cardinal questions in nitric oxide biology. J. Biol. Chem. 285(26), 19699-19704 (2010).

40 Stamati K, Mudera V, Cheema U. Evolution of oxygen utilization in multicellular organisms and implications for cell signalling in tissue engineering. J. Tissue Eng. 2(1), 2041731411432365 (2011).

41 Crapo JD, Oury T, Rabouille C, Slot JW, Chang LY. Copper, zinc superoxide dismutase is primarily a cytosolic protein in human cells. Proc. Natl Acad. Sci. USA 89(21), 10405-10409 (1992).

42 Malhotra JD, Kaufman RJ. Endoplasmic reticulum stress and oxidative stress: a vicious cycle or a double-edged sword? Antioxid. Redox Signal. 9(12), 2277-2293 (2007).

43 Lodhi IJ, Semenkovich CF. Peroxisomes: a nexus for lipid metabolism and cellular signaling. Cell Metab. 19(3), 380-392 (2014).

44 Nordgren M, Fransen M. Peroxisomal metabolism and oxidative stress. Biochimie 98, 56-62 (2014).

45 Bienert GP, Chaumont F. Aquaporin-facilitated transmembrane diffusion of hydrogen peroxide. Biochim. Biophys. Acta 1840(5), 1596-1604 (2014). 
46 Lu J, Holmgren A. The thioredoxin antioxidant system. Free Radic. Biol. Med. 66, 75-87 (2014). redox regulation and diseases of cellular differentiation. Biochim. Biophys. Acta 1850(8), 1607-1621 (2015). mechanisms underlying chronic inflammation-associated cancers. Cancer Lett. 345(2), 164-173 (2014). Macrophages induce COX-2 expression in breast cancer cells: role of IL-1 $\beta$ autoamplification. Carcinogenesis 32(5), 695-702 (2011).

50 Berry C, Hamilton CA, Brosnan MJ et al. Investigation into the sources of superoxide in human blood vessels: angiotensin II increases superoxide production in human internal mammary arteries. Circulation 101(18), 2206-2212 (2000).

51 Wever RMF, van Dam T, van Rijn HJM, de Groot F, Rabelink TJ. Tetrahydrobiopterin regulates superoxide and nitric oxide generation by recombinant endothelial nitric oxide synthase. Biochem. Biophys. Res. Commun. 237(2), 340-344 (1997).

52 Vásquez-Vivar J, Kalyanaraman B, Martásek P et al. Superoxide generation by endothelial nitric oxide synthase: the influence of cofactors. Proc. Natl Acad. Sci. USA 95(16), 9220-9225 (1998).

53 Lin MI, Fulton D, Babbitt R et al. Phosphorylation of threonine 497 in endothelial nitric-oxide synthase coordinates the coupling of $\mathrm{L}$-arginine metabolism to efficient nitric oxide production. J. Biol. Chem. 278(45), 44719-44726 (2003).

$54 \mathrm{Ou}$ J, Ou Z, Ackerman AW, Oldham KT, Pritchard KA Jr. Inhibition of heat shock protein 90 (hsp90) in proliferating endothelial cells uncouples endothelial nitric oxide synthase activity. Free Radic. Biol. Med. 34(2), 269-276 (2003).

55 Yim MB, Kang JH, Yim HS, Kwak HS, Chock PB, Stadtman ER. A gain-of-function of an amyotrophic lateral sclerosis-associated $\mathrm{Cu}, \mathrm{Zn}$-superoxide dismutase mutant: an enhancement of free radical formation due to a decrease in Km for hydrogen peroxide. Proc. Natl Acad. Sci. USA 93(12), 5709-5714 (1996).

56 Crow JP, Sampson JB, Zhuang Y, Thompson JA, Beckman JS. Decreased zinc affinity of amyotrophic lateral sclerosis-associated superoxide dismutase mutants leads to enhanced catalysis of tyrosine nitration by peroxynitrite. J. Neurochem. 69(5), 1936-1944 (1997).

57 Góth L, Vitai M, Rass P, Sükei E, Páy A. Detection of a novel familial catalase mutation (Hungarian type D) and the possible risk of inherited catalase deficiency for diabetes mellitus. Electrophoresis 26(9), 1646-1649 (2005). enzyme expression and reactive oxygen species damage in prostatic intraepithelial neoplasia and cancer. Cancer 89(1), 123-134 (2000).

59 Min JY, Lim S-O, Jung G. Downregulation of catalase by reactive oxygen species via hypermethylation of $\mathrm{CpG}$ island II on the catalase promoter. FEBS Lett. 584(11), 2427-2432 (2010).
60 Farina M, Avila DS, da Rocha JBT, Aschner M. Metals, oxidative stress and neurodegeneration: a focus on iron, manganese and mercury. Neurochem. Int. 62(5), 575-594 (2013).

61 Doughan AK, Harrison DG, Dikalov SI. Molecular mechanisms of angiotensin II-mediated mitochondrial dysfunction: linking mitochondrial oxidative damage and vascular endothelial dysfunction. Circ. Res. 102(4), 488-496 (2008).

62 Rathore R, Zheng Y-M, Niu C-F et al. Hypoxia activates $\mathrm{NADPH}$ oxidase to increase [ROS] i and [Ca2+]i through the mitochondrial ROS-PKCepsilon signaling axis in pulmonary artery smooth muscle cells. Free Radic. Biol. Med. 45(9), 1223-1231 (2008).

63 Hwang NR, Yim S-H, Kim YM et al. Oxidative modifications of glyceraldehyde-3-phosphate dehydrogenase play a key role in its multiple cellular functions. Biochem. J. 423(2), 253-264 (2009).

64 Martínez-Revelles S, Avendaño MS, García-Redondo $\mathrm{AB}$ et al. Reciprocal relationship between reactive oxygen species and cyclooxygenase- 2 and vascular dysfunction in hypertension. Antioxid. Redox Signal. 18(1), 51-65 (2012).

65 Dixon SJ, Lemberg KM, Lamprecht MR et al. Ferroptosis: an iron-dependent form of nonapoptotic cell death. Cell 149(5), 1060-1072 (2012).

66 Circu ML, Aw TY. Reactive oxygen species, cellular redox systems and apoptosis. Free Radic. Biol. Med. 48(6), 749-762 (2010).

67 Gehrmann W, Elsner M, Lenzen S. Role of metabolically generated reactive oxygen species for lipotoxicity in pancreatic $\beta$-cells. Diabetes Obes. Metab. 12(Suppl. 2), 149-158 (2010).

68 Angelova PR, Horrocks MH, Klenerman D, Gandhi S, Abramov AY, Shchepinov MS. Lipid peroxidation is essential for $\alpha$-synuclein-induced cell death. J. Neurochem. 133(4), 582-589 (2015).

69 Meira LB, Bugni JM, Green SL et al. DNA damage induced by chronic inflammation contributes to colon carcinogenesis in mice. J. Clin. Invest. 118(7), 2516-2525 (2008).

70 Remmen HV, Ikeno Y, Hamilton M et al. Life-long reduction in MnSOD activity results in increased DNA damage and higher incidence of cancer but does not accelerate aging. Physiol. Genomics 16(1), 29-37 (2003).

71 Mahalingaiah PKS, Singh KP. Chronic oxidative stress increases growth and tumorigenic potential of MCF-7 breast cancer cells. PLoS ONE 9(1), e87371 (2014).

72 Al-Shobaili HA, Al Robaee AA, Alzolibani AA, Rasheed Z. Antibodies against 4-hydroxy-2-nonenal modified epitopes recognized chromatin and its oxidized forms: role of chromatin, oxidized forms of chromatin and 4-hydroxy2-nonenal modified epitopes in the etiopathogenesis of SLE. Dis. Markers 33(1), 19-34 (2012).

73 Lunec J, Herbert K, Blount S, Griffiths HR, Emery P. 8-Hydroxydeoxyguanosine: a marker of oxidative DNA damage in systemic lupus erythematosus. FEBS Lett. 348(2), 131-138 (1994).

74 Görlach A, Brandes RP, Nguyen K, Amidi M, Dehghani F, Busse R. A gp91phox containing NADPH oxidase selectively 
expressed in endothelial cells is a major source of oxygen radical generation in the arterial wall. Circ. Res. 87(1), 26-32 (2000).

75 Julienne H, Zoufir A, Audit B, Arneodo A. Human genome replication proceeds through four chromatin states. PLoS Comput. Biol. 9(10), e1003233 (2013).

76 Yan S-J, Lim SJ, Shi S, Dutta P, Li WX. Unphosphorylated STAT and heterochromatin protect genome stability. FASEB J. 25(1), 232-241 (2011).

77 Wang D, Zhou J, Liu X et al. Methylation of SUV39H1 by SET7/9 results in heterochromatin relaxation and genome instability. Proc. Natl Acad. Sci. USA 110(14), 5516-5521 (2013).

78 Larson K, Yan S-J, Tsurumi A et al. Heterochromatin formation promotes longevity and represses ribosomal RNA synthesis. PLoS Genet. 8(1), e1002473 (2012).

79 Zhu Q, Pao GM, Huynh AM et al. BRCA1 tumour suppression occurs via heterochromatin-mediated silencing. Nature 477(7363), 179-184 (2011).

80 Bernard P, Maure JF, Partridge JF, Genier S, Javerzat JP, Allshire RC. Requirement of heterochromatin for cohesion at centromeres. Science 294(5551), 2539-2542 (2001).

81 Peters AHFM, O'Carroll D, Scherthan $\mathrm{H}$ et al. Loss of the Suv39h histone methyltransferases impairs mammalian heterochromatin and genome stability. Cell 107(3), 323-337 (2001).

82 Halicka HD, Zhao H, Podhorecka M, Traganos F, Darzynkiewicz Z. Cytometric detection of chromatin relaxation, an early reporter of DNA damage response. Cell Cycle Georget. Tex. 8(14), 2233-2237 (2009).

83 Frost B, Hemberg M, Lewis J, Feany MB. Tau promotes neurodegeneration through global chromatin relaxation. Nat. Neurosci. 17(3), 357-366 (2014).

-. This study is one of few that directly link oxidative stress to disease pathogenesis. It describes how tau can induce neuronal cell death in an oxidative stress-dependent manner.

84 Khurana V, Lu Y, Steinhilb ML, Oldham S, Shulman JM, Feany MB. TOR-mediated cell-cycle activation causes neurodegeneration in a drosophila tauopathy model. Curr. Biol. 16(3), 230-241 (2006).

85 Bosch-Presegué L, Raurell-Vila H, Marazuela-Duque A et al. Stabilization of Suv39H1 by SirT1 is part of oxidative stress response and ensures genome protection. Mol. Cell 42(2), 210-223 (2011).

- Provides a mechanism for direct regulation of heterochromatin stability by oxidative stress.

86 Dixit K, Khan MA, Sharma YD, Moinuddin, Alam K. Physicochemical studies on peroxynitrite-modified $\mathrm{H} 3$ histone. Int. J. Biol. Macromol. 46(1), 20-26 (2010).

87 Khan MA, Dixit K, Moinuddin, Arif Z, Alam K. Studies on peroxynitrite-modified $\mathrm{H} 1$ histone: implications in systemic lupus erythematosus. Biochimie 97, 104-113 (2014).

88 Ayala A, Munoz MF, Arguelles S. Lipid Peroxidation: production, metabolism, and signaling mechanisms of malondialdehyde and 4-hydroxy-2-nonenal, lipid peroxidation: production, metabolism, and signaling mechanisms of malondialdehyde and 4-hydroxy-2nonenal. Oxidative Med. Cell. Longev. Oxidative Med. Cell. Longev. 2014, e360438 (2014).

89 Beisswenger PJ, Howell SK, Smith K, Szwergold BS. Glyceraldehyde-3-phosphate dehydrogenase activity as an independent modifier of methylglyoxal levels in diabetes. Biochim. Biophys. Acta 1637(1), 98-106 (2003).

90 Niwa T. 3-Deoxyglucosone: metabolism, analysis, biological activity, and clinical implication. J. Chromatogr. B. Biomed. Sci. App. 731(1), 23-36 (1999).

91 Singh R, Barden A, Mori T, Beilin L. Advanced glycation end-products: a review. Diabetologia 44(2), 129-146 (2001).

92 Nagai R, Ikeda K, Higashi T et al. Hydroxyl radical mediates $\mathrm{N}$-(carboxymethyl)lysine formation from amadori product. Biochem. Biophys. Res. Commun. 234(1), 167-172 (1997).

93 Fu MX, Wells-Knecht KJ, Blackledge JA, Lyons TJ, Thorpe SR, Baynes JW. Glycation, glycoxidation, and cross-linking of collagen by glucose. Kinetics, mechanisms, and inhibition of late stages of the Maillard reaction. Diabetes 43(5), 676-683 (1994).

94 Baumann M. Role of advanced glycation end products in hypertension and cardiovascular risk: human studies. J. Am. Soc. Hypertens. JASH 6(6), 427-435 (2012).

95 Srikanth V, Maczurek A, Phan T et al. Advanced glycation endproducts and their receptor RAGE in Alzheimer's disease. Neurobiol. Aging 32(5), 763-777 (2011).

96 Alzolibani AA, Al Robaee AA, Al-Shobaili HA, Rasheed Z. 4-Hydroxy-2-nonenal modified histone-H2A: a possible antigenic stimulus for systemic lupus erythematosus autoantibodies. Cell. Immunol. 284(1), 154-162 (2013).

97 Ashraf JM, Ahmad S, Rabbani G et al. Physicochemical analysis of structural alteration and advanced glycation end products generation during glycation of $\mathrm{H} 2 \mathrm{~A}$ histone by 3-deoxyglucosone. IUBMB Life 66(10), 686-693 (2014).

98 Ashraf JM, Rabbani G, Ahmad S et al. Glycation of H1 histone by 3-deoxyglucosone: effects on protein structure and generation of different advanced glycation end products. PLoS ONE 10(6), e0130630 (2015).

99 Ashraf JM, Ahmad S, Rabbani G et al. 3-Deoxyglucosone: a potential glycating agent accountable for structural alteration in $\mathrm{H} 3$ histone protein through generation of different AGEs. PLoS ONE 10(2), e0116804 (2015).

100 Mir AR, Uddin, M Alam K, Ali A. Methylglyoxal mediated conformational changes in histone $\mathrm{H} 2 \mathrm{~A}$-generation of carboxyethylated advanced glycation end products. Int. J. Biol. Macromol. 69, 260-266 (2014).

101 Rahmanpour R, Bathaie SZ. Histone H1 structural changes and its interaction with DNA in the presence of high glucose concentration in vivo and in vitro. J. Biomol. Struct. Dyn. 28(4), 575-586 (2011).

102 Galligan JJ, Rose KL, Beavers WN et al. Stable histone adduction by 4-oxo-2-nonenal: a potential link between oxidative stress and epigenetics. J. Am. Chem. Soc. 136(34), 11864-11866 (2014).

103 Chen D, Fang L, Li H, Tang M, Jin C. Cigarette smoke component acrolein modulates chromatin assembly by 
inhibiting histone acetylation. J. Biol. Chem. 288(30), 21678-21687 (2013).

-• This is the only study linking a pathological stimulus to direct histone carbonylation and also dissecting a mechanism for its influence on gene expression.

104 Cervantes-Laurean D, Roberts MJ, Jacobson EL, Jacobson MK. Nuclear proteasome activation and degradation of carboxymethylated histones in human keratinocytes following glyoxal treatment. Free Radic. Biol. Med. 38(6), 786-795 (2005).

105 Manevich Y, Feinstein SI, Fisher AB. Activation of the antioxidant enzyme 1-CYS peroxiredoxin requires glutathionylation mediated by heterodimerization with

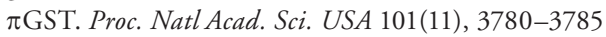
(2004).

106 Grek CL, Zhang J, Manevich Y, Townsend DM, Tew KD. Causes and consequences of cysteine s-glutathionylation. J. Biol. Chem. 288(37), 26497-26504 (2013).

107 Luca A de, Moroni N, Serafino A et al. Treatment of doxorubicin-resistant MCF7/Dx cells with nitric oxide causes histone glutathionylation and reversal of drug resistance. Biochem. J. 440 (2), 175-183 (2011).

108 García-Giménez JL, Olaso G, Hake SB et al. Histone $\mathrm{H} 3$ glutathionylation in proliferating mammalian cells destabilizes nucleosomal structure. Antioxid. Redox Signal. 19(12), 1305-1320 (2013).

- Shows how histone glutathionylation affects chromatin structure and stimulates proliferation.

109 Balasubramanian S, Hurley LH, Neidle S. Targeting G-quadruplexes in gene promoters: a novel anticancer strategy? Nat. Rev. Drug Discov. 10(4), 261-275 (2011).

110 Clark DW, Phang T, Edwards MG, Geraci MW, Gillespie MN. Promoter G-quadruplex sequences are targets for base oxidation and strand cleavage during hypoxia-induced transcription. Free Radic. Biol. Med. 53(1), 51-59 (2012).

111 Ba X, Bacsi A, Luo J et al. 8-oxoguanine DNA glycosylase-1 augments proinflammatory gene expression by facilitating the recruitment of site-specific transcription factors. J. Immunol. 192(5), 2384-2394 (2014).

- Dissects a mechanism for how oxidative 'damage' to DNA can activate gene expression.

112 Valinluck V, Tsai H-H, Rogstad DK, Burdzy A, Bird A, Sowers LC. Oxidative damage to methyl-CpG sequences inhibits the binding of the methyl-CpG binding domain (MBD) of methyl-CpG binding protein 2 (MeCP2). Nucleic Acids Res. 32(14), 4100-4108 (2004).

113 Deaton AM, Bird A. CpG islands and the regulation of transcription. Genes Dev. 25(10), 1010-1022 (2011).

114 Dickson KM, Gustafson CB, Young JI, Züchner S, Wang G. Ascorbate-induced generation of 5-hydroxymethylcytosine is unaffected by varying levels of iron and 2-oxoglutarate. Biochem. Biophys. Res. Commun. 439(4), 522-527 (2013).

115 Ponnaluri VKC, Maciejewski JP, Mukherji M. A mechanistic overview of TET-mediated 5-methylcytosine oxidation. Biochem. Biophys. Res. Commun. 436(2), 115-120 (2013).
116 Mastroeni D, Grover A, Delvaux E, Whiteside C, Coleman PD, Rogers J. Epigenetic changes in Alzheimer's disease: decrements in DNA methylation. Neurobiol. Aging 31(12), 2025-2037 (2010).

117 Volkmar M, Dedeurwaerder S, Cunha DA et al. DNA methylation profiling identifies epigenetic dysregulation in pancreatic islets from type 2 diabetic patients. $E M B O J$. 31(6), 1405-1426 (2012).

118 Cheishvili D, Stefanska B, Yi C et al. A common promoter hypomethylation signature in invasive breast, liver and prostate cancer cell lines reveals novel targets involved in cancer invasiveness. Oncotarget 6(32), 33253-33268 (2015).

119 Leodolter A, Alonso S, González B et al. Somatic DNA hypomethylation in $H$. pylori-associated high-risk gastritis and gastric cancer: enhanced somatic hypomethylation associates with advanced stage cancer. Clin. Transl. Gastroenterol. 6, e85 (2015).

120 Gravina GL, Ranieri G, Muzi P et al. Increased levels of DNA methyltransferases are associated with the tumorigenic capacity of prostate cancer cells. Oncol. Rep. 29(3), 1189-1195 (2013).

121 Avila MA, Corrales FJ, Ruiz F et al. Specific interaction of methionine adenosyltransferase with free radicals. BioFactors 8(1), 27-32 (1998).

122 Pajares MA, Durán C, Corrales F, Pliego MM, Mato JM. Modulation of rat liver S-adenosylmethionine synthetase activity by glutathione. J. Biol. Chem. 267(25), 17598-17605 (1992).

123 Jarrett JT, Hoover DM, Ludwig ML, Matthews RG. The mechanism of adenosylmethionine-dependent activation of methionine synthase: a rapid kinetic analysis of Intermediates in reductive methylation of $\mathrm{Cob}(\mathrm{II})$ alamin enzyme. Biochemistry (Mosc.). 37(36), 12649-12658 (1998).

124 Lu SC. Regulation of glutathione synthesis. Mol. Aspects Med. 30(1), 42-59 (2009).

125 Cyr AR, Domann FE. The redox basis of epigenetic modifications: from mechanisms to functional consequences. Antioxid. Redox Signal. 15(2), 551-589 (2011).

126 Mosharov E, Cranford MR, Banerjee R. The quantitatively important relationship between homocysteine metabolism and glutathione synthesis by the transsulfuration pathway and its regulation by redox changes. Biochemistry (Mosc.). 39(42), 13005-13011 (2000).

127 Kloypan C, Srisa-Art M, Mutirangura A, Boonla C. LINE-1 hypomethylation induced by reactive oxygen species is mediated via depletion of S-adenosylmethionine. Cell Biochem. Funct. 33(6), 375-384 (2015).

128 Lertratanangkoon K, Wu CJ, Savaraj N, Thomas ML. Alterations of DNA methylation by glutathione depletion. Cancer Lett. 120 (2), 149-156 (1997).

129 Valinluck V, Sowers LC. Endogenous cytosine damage products alter the site selectivity of human DNA maintenance methyltransferase DNMT1. Cancer Res. 67(3), 946-950 (2007).

130 Niu Y, DesMarais TL, Tong Z, Yao Y, Costa M. Oxidative stress alters global histone modification and DNA methylation. Free Radic. Biol. Med. 82, 22-28 (2015). 
- Shows that oxidative stress modulates the activities of DNA methyltransferases, histone demethylases and histone deacetylases.

131 Delatte B, Jeschke J, Defrance M et al. Genome-wide hydroxymethylcytosine pattern changes in response to oxidative stress. Sci. Rep. 5, 12714 (2015).

- Shows that hydroxymethylcytosine levels are altered in genes involved in oxidative stress-related pathways.

132 Xin Y-J, Yuan B, Yu B et al. Tet1-mediated DNA demethylation regulates neuronal cell death induced by oxidative stress. Sci. Rep. 5, 7645 (2015).

- Provides insight into the regulation of neuronal cell death by changes in DNA methylation, which increases sensitivity of neurons to oxidative stress.

133 Xiao M, Yang H, Xu W et al. Inhibition of $\alpha$-KG-dependent histone and DNA demethylases by fumarate and succinate that are accumulated in mutations of $\mathrm{FH}$ and $\mathrm{SDH}$ tumor suppressors. Genes Dev. 26(12), 1326-1338 (2012).

134 Frizzell N, Thomas SA, Carson JA, Baynes JW. Mitochondrial stress causes increased succination of proteins in adipocytes in response to glucotoxicity. Biochem. J. 445(2), 247-254 (2012).

135 Tretter L, Adam-Vizi V. Inhibition of Krebs cycle enzymes by hydrogen peroxide: a key role of [alpha]-ketoglutarate dehydrogenase in limiting NADH production under oxidative stress. J. Neurosci. 20(24), 8972-8979 (2000).

136 O'Hagan HM, Wang W, Sen S et al. Oxidative damage targets complexes containing DNA methyltransferases, SIRT1, and Polycomb members to promoter CpG islands. Cancer Cell 20 (5), 606-619 (2011).

-. Dissects an oxidative stress-dependent mechanism for the observed global DNA hypomethylation but specific CpG island hypermethylation in cancer cells.

137 Ding N, Bonham EM, Hannon BE, Amick TR, Baylin SB, O'Hagan HM. Mismatch repair proteins recruit DNA methyltransferase 1 to sites of oxidative DNA damage. J. Mol. Cell Biol. doi:10.1093/jmcb/mjv050 (2015) (Epub ahead of print).

- Provides further mechanistic insight into the specific recruitment of DNMT1 to oxidatively modified CpG islands.

138 Kooistra SM, Helin K. Molecular mechanisms and potential functions of histone demethylases. Nat. Rev. Mol. Cell Biol. 13(5), 297-311 (2012).

139 Sullivan LB, Martinez-Garcia E, Nguyen H et al. The proto-oncometabolite fumarate binds glutathione to amplify ROS-dependent signaling. Mol. Cell 51(2), 236-248 (2013)

140 Hickok JR, Vasudevan D, Antholine WE, Thomas DD. Nitric oxide modifies global histone methylation by inhibiting Jumonji C domain-containing demethylases. J. Biol. Chem. 288(22), 16004-16015 (2013).

141 Hitchler MJ, Domann FE. Redox regulation of the epigenetic landscape in cancer: a role for metabolic reprogramming in remodeling the epigenome. Free Radic. Biol. Med. 53(11), 2178-2187 (2012).
142 Kera Y, Katoh Y, Ohta M, Matsumoto M, TakanoYamamoto T, Igarashi K. Methionine adenosyltransferase II-dependent histone $\mathrm{H} 3 \mathrm{~K} 9$ methylation at the $\mathrm{COX}-2$ gene locus. J. Biol. Chem. 288(19), 13592-13601 (2013).

143 Ruijter AJM de, Gennip AH van, Caron HN, Kemp S, Kuilenburg ABP van. Histone deacetylases (HDACs): characterization of the classical HDAC family. Biochem. J. 370(3), 737-749 (2003).

144 Marks PA, Rifkind RA, Richon VM, Breslow R, Miller T, Kelly WK. Histone deacetylases and cancer: causes and therapies. Nat. Rev. Cancer 1(3), 194-202 (2001).

145 Delcuve GP, Khan DH, Davie JR. Roles of histone deacetylases in epigenetic regulation: emerging paradigms from studies with inhibitors. Clin. Epigenetics 4(1), 5 (2012).

146 Lombardi PM, Cole KE, Dowling DP, Christianson DW. Structure, mechanism, and inhibition of histone deacetylases and related metalloenzymes. Curr. Opin. Struct. Biol. 21(6), 735-743 (2011).

147 Khan O, La Thangue NB. HDAC inhibitors in cancer biology: emerging mechanisms and clinical applications. Immunol. Cell Biol. 90 (1), 85-94 (2012).

148 Tanny JC, Moazed D. Coupling of histone deacetylation to NAD breakdown by the yeast silencing protein Sir2: evidence for acetyl transfer from substrate to an NAD breakdown product. Proc. Natl Acad. Sci. USA 98(2), 415-420 (2001).

149 Tanner KG, Landry J, Sternglanz R, Denu JM. Silent information regulator 2 family of NAD-dependent histone/ protein deacetylases generates a unique product, 1- $O$-acetylADP-ribose. Proc. Natl Acad. Sci. USA 97(26), 14178-14182 (2000).

150 Moodie FM, Marwick JA, Anderson CS et al. Oxidative stress and cigarette smoke alter chromatin remodeling but differentially regulate NF- $\mathrm{\kappa B}$ activation and proinflammatory cytokine release in alveolar epithelial cells. FASEB J. 18(15), 1897-1899 (2004).

151 Doyle K, Fitzpatrick FA. Redox signaling, alkylation (carbonylation) of conserved cysteines inactivates class I histone deacetylases 1, 2, and 3 and antagonizes their transcriptional repressor function. J. Biol. Chem. 285(23), 17417-17424 (2010)

152 Kornberg MD, Sen N, Hara MR et al. GAPDH mediates nitrosylation of nuclear proteins. Nat. Cell Biol. 12(11), 1094-1100 (2010).

153 Nott A, Watson PM, Robinson JD, Crepaldi L, Riccio A. $\mathrm{S}$-nitrosylation of histone deacetylase 2 induces chromatin remodelling in neurons. Nature 455(7211), 411-415 (2008)

154 Colussi C, Mozzetta C, Gurtner A et al. HDAC2 blockade by nitric oxide and histone deacetylase inhibitors reveals a common target in Duchenne muscular dystrophy treatment. Proc. Natl Acad. Sci. USA 105(49), 19183 -19187 (2008).

155 Bhaskara S, Knutson SK, Jiang G et al. Hdac3 is essential for the maintenance of chromatin structure and genome stability. Cancer Cell 18(5), 436-447 (2010).

156 Dovey OM, Foster CT, Conte N et al. Histone deacetylase 1 and 2 are essential for normal T-cell development and genomic stability in mice. Blood 121(8), 1335-1344 (2013). 
157 Heideman MR, Wilting RH, Yanover E et al. Dosagedependent tumor suppression by histone deacetylases 1 and 2 through regulation of c-Myc collaborating genes and $\mathrm{p} 53$ function. Blood 121(11), 2038-2050 (2013).

158 Santoro F, Botrugno OA, Zuffo RD et al. A dual role for $\mathrm{Hdac1}$ : oncosuppressor in tumorigenesis, oncogene in tumor maintenance. Blood 121(17), 3459-3468 (2013).

159 Shimazu T, Hirschey MD, Newman J et al. Suppression of oxidative stress by $\beta$-hydroxybutyrate, an endogenous histone deacetylase inhibitor. Science 339(6116), 211-214 (2013).

160 Caito S, Rajendrasozhan S, Cook S et al. SIRT1 is a redoxsensitive deacetylase that is post-translationally modified by oxidants and carbonyl stress. FASEB J. 24(9), 3145-3159 (2010).

161 Shao D, Fry JL, Han J et al. A redox-resistant sirtuin-1 mutant protects against hepatic metabolic and oxidant stress. J. Biol. Chem. 289(11), 7293-7306 (2014).

162 Yao H, Chung S, Hwang J-W et al. SIRT1 protects against emphysema via $\mathrm{FOXO3}$-mediated reduction of premature senescence in mice. J. Clin. Invest. 122(6), 2032-2045 (2012).

163 Ota H, Eto M, Kano MR et al. Cilostazol Inhibits oxidative stress-induced premature senescence via upregulation of Sirt1 in human endothelial cells. Arterioscler. Thromb. Vasc. Biol. 28(9), 1634-1639 (2008).

164 Yang S-R, Wright J, Bauter M, Seweryniak K, Kode A, Rahman I. Sirtuin regulates cigarette smoke-induced proinflammatory mediator release via RelA/p65 NF-kappaB in macrophages in vitro and in rat lungs in vivo: implications for chronic inflammation and aging. Am. J. Physiol. Lung Cell Mol. Physiol. 292(2), L567-L576 (2007).

165 Fritz KS, Galligan JJ, Smathers RL et al. 4-Hydroxynonenal inhibits SIRT3 via thiol-specific modification. Chem. Res. Toxicol. 24(5), 651-662 (2011).

166 Iwahara T, Bonasio R, Narendra V, Reinberg D. SIRT3 functions in the nucleus in the control of stress-related gene expression. Mol. Cell Biol. 32(24), 5022-5034 (2012).

$167 \mathrm{Hu}$ S, Liu H, Ha Y et al. Posttranslational modification of Sirt6 activity by peroxynitrite. Free Radic. Biol. Med. 79, 176-185 (2015)

168 Sebastián C, Zwaans BMM, Silberman DM et al. The histone deacetylase SIRT6 is a tumor suppressor that controls cancer metabolism. Cell 151(6), 1185-1199 (2012).

169 Liu Y, Hernández-Ochoa EO, Randall WR, Schneider MF. NOX2-dependent ROS is required for HDAC5 nuclear efflux and contributes to HDAC4 nuclear efflux during intense repetitive activity of fast skeletal muscle fibers. $\mathrm{Am}$. J. Physiol. Cell Physiol. 303(3), C334-C347 (2012).

170 Lu J, McKinsey TA, Nicol RL, Olson EN. Signal-dependent activation of the MEF2 transcription factor by dissociation from histone deacetylases. Proc. Natl Acad. Sci. USA 97(8), 4070-4075 (2000).

171 Hwang J, Yao H, Caito S, Sundar IK, Rahman I. Redox regulation of SIRT1 in inflammation and cellular senescence. Free Radic. Biol. Med. 61, 95-110 (2013).

172 Agudelo M, Gandhi N, Saiyed Z et al. Effects of alcohol on histone deacetylase 2 (HDAC2) and the neuroprotective role of trichostatin A (TSA). Alcohol. Clin. Exp. Res. 35(8), 1550-1556 (2011).

173 Castonguay Z, Auger C, Thomas SC, Chahma M'hamed, Appanna VD. Nuclear lactate dehydrogenase modulates histone modification in human hepatocytes. Biochem. Biophys. Res. Commun. 454(1), 172-177 (2014).

174 Banerjee T, Chakravarti D. A peek into the complex realm of histone phosphorylation. Mol. Cell Biol. 31(24), 4858-4873 (2011).

175 Ye B, Hou N, Xiao L, Xu Y, Xu H, Li F. Dynamic monitoring of oxidative DNA double-strand break and repair in cardiomyocytes. Cardiovasc. Pathol. Off. J. Soc. Cardiovasc. Pathol. 25(2), 93-100 (2016).

176 Mah L-J, El-Osta A, Karagiannis TC. gammaH2AX: a sensitive molecular marker of DNA damage and repair. Leukemia 24(4), 679-686 (2010).

177 Katsube T, Mori M, Tsuji $\mathrm{H}$ et al. Most hydrogen peroxideinduced histone $\mathrm{H} 2 \mathrm{AX}$ phosphorylation is mediated by ATR and is not dependent on DNA double-strand breaks. J. Biochem. 156(2), 85-95 (2014).

178 Marwick JA, Tudor C, Khorasani N, Michaeloudes C, Bhavsar PK, Chung KF. Oxidants induce a corticosteroid-insensitive phosphorylation of histone 3 at serine 10 in monocytes. PLoS ONE 10(4), e0124961 (2015).

179 Jeong M-W, Kang T-H, Kim W, Choi YH, Kim K-T. Mitogenactivated protein kinase phosphatase 2 regulates histone $\mathrm{H} 3$ phosphorylation via interaction with vaccinia-related kinase 1 . Mol. Biol. Cell 24(3), 373-384 (2013).

180 Rusnak F, Reiter T. Sensing electrons: protein phosphatase redox regulation. Trends Biochem. Sci. 25(11), 527-529 (2000).

181 Iyengar S, Farnham PJ. KAP1 protein: an enigmatic master regulator of the genome. J. Biol. Chem. 286(30), 26267-26276 (2011).

182 Wei N, Shi Y, Truong LN et al. Oxidative stress diverts tRNA synthetase to nucleus for protection against DNA damage. Mol. Cell 56(2), 323-332 (2014).

- Provides an explanation for how oxidative stress drives expression of DNA repair genes by sequestering TRIM28.

183 Higo S, Asano Y, Kato $\mathrm{H}$ et al. Isoform-specific intermolecular disulfide bond formation of heterochromatin protein 1 (HP1). J. Biol. Chem. 285(41), 31337-31347 (2010).

- Shows that HP1 $\gamma$ sequesters TRIM28 under oxidative stress conditions.

184 Whitelaw NC, Chong S, Morgan DK et al. Reduced levels of two modifiers of epigenetic gene silencing, Dnmt3a and Trim28, cause increased phenotypic noise. Genome Biol. 11(11), R111 (2010).

185 Štros M. HMGB proteins: interactions with DNA and chromatin. Biochim. Biophys. Acta BBA 1799(1), 101-113 (2010).

186 Polanská E, Pospísilová Š, Štros M. Binding of histone H1 to DNA is differentially modulated by redox state of HMGB1. PLoS ONE 9(2), e89070 (2014).

-• Shows how the functions of HMGB1 are altered by oxidation. It is the only study that describes intracellular effects of oxidized HMGB1 independent of RAGE. 
187 Fiume R, Stijf-Bultsma Y, Shah ZH et al. PIP4K and the role of nuclear phosphoinositides in tumour suppression. Biochim. Biophys. Acta 1851(6), 898-910 (2015).

188 Keune W jan, Bultsma Y, Sommer L, Jones D, Divecha N. Phosphoinositide signalling in the nucleus. Adv. Enzyme Regul. 51(1), 91-99 (2011).

189 Jones DR, Bultsma Y, Keune W-J et al. Nuclear PtdIns5P as a transducer of stress signaling: an in vivo role for PIP4Kbeta. Mol. Cell 23(5), 685-695 (2006).

190 Attia SM, Ahmad SF, Harisa GI, Mansour AM, El Sayed ESM, Bakheet SA. Wogonin attenuates etoposide-induced oxidative DNA damage and apoptosis via suppression of oxidative DNA stress and modulation of OGG1 expression. Food Chem. Toxicol. 59, 724-730 (2013).

191 Gozani O, Karuman P, Jones DR et al. The PHD finger of the chromatin-associated protein ING2 functions as a nuclear phosphoinositide receptor. Cell 114(1), 99-111 (2003).

192 Pedeux R, Sengupta S, Shen JC et al. ING2 regulates the onset of replicative senescence by induction of p300-dependent p53 acetylation. Mol. Cell Biol. 25(15), 6639-6648 (2005).

193 Doyon Y, Cayrou C, Ullah M et al. ING tumor suppressor proteins are critical regulators of chromatin acetylation required for genome expression and perpetuation. Mol. Cell 21(1), 51-64 (2006).

194 Bua DJ, Martin GM, Binda O, Gozani O. Nuclear phosphatidylinositol-5-phosphate regulates ING2 stability at discrete chromatin targets in response to DNA damage. Sci. Rep. 3, 2137 (2013).

- Shows how PI(5)P regulates gene expression via ING2 in response to etoposide treatment.

195 Stijf-Bultsma Y, Sommer L, Tauber M et al. The basal transcription complex component TAF3 transduces changes in nuclear phosphoinositides into transcriptional output. Mol. Cell 58(3), 453-467 (2015).

- Provides insight into the regulation of TAF3 by PI(5)P.

196 Bronner C. Control of DNMT1 abundance in epigenetic inheritance by acetylation, ubiquitylation, and the histone code. Sci. Signal. 4(157), pe3 (2011).

197 Gelato KA, Tauber M, Ong MS et al. Accessibility of different histone H3-binding domains of UHRF1 is allosterically regulated by phosphatidylinositol 5-phosphate. Mol. Cell 54(6), 905-919 (2014).

- Shows how the structure of UHRF1 is regulated by PI(5)P.

198 Montero D, Walther G, Stehouwer CDA, Houben AJHM, Beckman JA, Vinet A. Effect of antioxidant vitamin supplementation on endothelial function in type 2 diabetes mellitus: a systematic review and meta-analysis of randomized controlled trials. Obes. Rev. 15(2), 107-116 (2014).

199 Rafieian-Kopaie M, Nasri H. On the Occasion of World Cancer Day 2015; the possibility of cancer prevention or treatment with antioxidants: the ongoing cancer prevention researches. Int. J. Prev. Med. 6, 108 (2015).

200 Galasko DR, Peskind E, Clark CM et al. Antioxidants for Alzheimer disease: a randomized clinical trial with cerebrospinal fluid biomarker measures. Arch. Neurol. 69(7), 836-841 (2012)

201 Harrison FE, Allard J, Bixler R et al. Antioxidants and cognitive training interact to affect oxidative stress and memory in APP/PSEN1 mice. Nutr. Neurosci. 12(5), 203-218 (2009).

202 Jin H, Kanthasamy A, Ghosh A, Anantharam V, Kalyanaraman B, Kanthasamy AG. Mitochondria-targeted antioxidants for treatment of Parkinson's disease: preclinical and clinical outcomes. Biochim. Biophys. Acta 1842(8), 1282-1294 (2014) 